\title{
Dysregulated Immunological Functionome and Dysfunctional Metabolic Pathway Recognized for the Pathogenesis of Borderline Ovarian Tumors by Integrative Polygenic Analytics
}

\author{
Chia-Ming Chang ${ }^{1,2,3}{ }^{\oplus}$, Yao-Feng Li $\left.{ }^{4}{ }^{(}\right)$, Hsin-Chung Lin ${ }^{5,6}$, Kai-Hsi Lu ${ }^{7}$, Tzu-Wei Lin ${ }^{8}$, Li-Chun Liu ${ }^{9,10}{ }^{\circ}$, \\ Kuo-Min Su ${ }^{9,11, *,+}+$ and Cheng-Chang Chang ${ }^{9,11, *,+} \mathbb{D}$
}

Citation: Chang, C.-M.; Li, Y.-F.; Lin, H.-C.; Lu, K.-H.; Lin, T.-W.; Liu, L.-C.; Su, K.-M.; Chang, C.-C. Dysregulated Immunological Functionome and Dysfunctional Metabolic Pathway Recognized for the Pathogenesis of Borderline Ovarian Tumors by Integrative Polygenic Analytics. Int. J. Mol. Sci. 2021, 22, 4105. https:// doi.org/10.3390/ijms22084105

Academic Editor: Carmela Ricciardelli

Received: 16 March 2021

Accepted: 13 April 2021

Published: 15 April 2021

Publisher's Note: MDPI stays neutral with regard to jurisdictional claims in published maps and institutional affiliations.

Copyright: (c) 2021 by the authors. Licensee MDPI, Basel, Switzerland. This article is an open access article distributed under the terms and conditions of the Creative Commons Attribution (CC BY) license (https:// creativecommons.org/licenses/by/ $4.0 /)$.
School of Medicine, National Yang-Ming University, Taipei 112, Taiwan; cm_chang@vghtpe.gov.tw Department of Obstetrics and Gynecology, Taipei Veterans General Hospital, Taipei 112, Taiwan School of Medicine, National Yang Ming Chiao Tung University, Taipei 112, Taiwan

4 Department of Pathology, Tri-Service General Hospital, National Defense Medical Center, Taipei 114, Taiwan; liyaofeng1109@gmail.com

5 Division of Clinical Pathology, Department of Pathology, Tri-Service General Hospital, National Defense Medical Center, Taipei 114, Taiwan; Hsinchunglin@gmail.com

6 Graduate Institute of Pathology and Parasitology, National Defense Medical Center, Taipei 114, Taiwan

7 Department of Medical Research and Education, Cheng-Hsin General Hospital, Taipei 112, Taiwan; lionel.lu@gmail.com

8 Department of Medical Research, Taipei Veterans General Hospital, Taipei 112, Taiwan; backyard0826@gmail.com

9 Department of Obstetrics and Gynecology, Tri-Service General Hospital, National Defense Medical Center, Taipei 114, Taiwan; lvita.tw@gmail.com

10 Division of Obstetrics and Gynecology, Tri-Service General Hospital Songshan Branch, National Defense Medical Center, Taipei 105, Taiwan

11 Graduate Institute of Medical Sciences, National Defense Medical Center, Taipei 114, Taiwan

* Correspondence: aeolusfield@hotmail.com (K.-M.S.); obsgynchang@gmail.com (C.-C.C.); Tel.: +886-2-8792-7205 (C.-C.C.) ; +886-2-8792-7205 (K.-M.S.)

+ Equal contribution.

Abstract: The pathogenesis and molecular mechanisms of ovarian low malignant potential (LMP) tumors or borderline ovarian tumors (BOTs) have not been fully elucidated to date. Surgery remains the cornerstone of treatment for this disease, and diagnosis is mainly made by histopathology to date. However, there is no integrated analysis investigating the tumorigenesis of BOTs with open experimental data. Therefore, we first utilized a functionome-based speculative model from the aggregated obtainable datasets to explore the expression profiling data among all BOTs and two major subtypes of BOTs, serous BOTs (SBOTs) and mucinous BOTs (MBOTs), by analyzing the functional regularity patterns and clustering the separate gene sets. We next prospected and assembled the association between these targeted biomolecular functions and their related genes. Our research found that BOTs can be accurately recognized by gene expression profiles by means of integrative polygenic analytics among all BOTs, SBOTs, and MBOTs; the results exhibited the top 41 common dysregulated biomolecular functions, which were sorted into four major categories: immune and inflammatory response-related functions, cell membrane- and transporter-related functions, cell cycleand signaling-related functions, and cell metabolism-related functions, which were the key elements involved in its pathogenesis. In contrast to previous research, we identified 19 representative genes from the above classified categories (IL6, CCR2 for immune and inflammatory response-related functions; IFNG, ATP1B1, GAS6, and PSEN1 for cell membrane- and transporter-related functions; CTNNB1, GATA3, and IL1B for cell cycle- and signaling-related functions; and AKT1, SIRT1, IL4, PDGFB, MAPK3, SRC, TWIST1, TGFB1, ADIPOQ, and PPARGC1A for cell metabolism-related functions) that were relevant in the cause and development of BOTs. We also noticed that a dysfunctional pathway of galactose catabolism had taken place among all BOTs, SBOTs, and MBOTs from the analyzed gene set databases of canonical pathways. With the help of immunostaining, we verified significantly higher performance of interleukin 6 (IL6) and galactose-1-phosphate uridylyltransferase (GALT) among BOTs than the controls. In conclusion, a bioinformatic platform of gene-set integrative 
molecular functionomes and biophysiological pathways was constructed in this study to interpret the complicated pathogenic pathways of BOTs, and these important findings demonstrated the dysregulated immunological functionome and dysfunctional metabolic pathway as potential roles during the tumorigenesis of BOTs and may be helpful for the diagnosis and therapy of BOTs in the future.

Keywords: borderline ovarian tumors (BOTs); gene ontology (GO); functionome-based and datadriven analysis; immune and inflammatory response; cell membrane and transporter; cell cycle and signaling; cell metabolism; galactose catabolism

\section{Introduction}

Ovarian low malignancy potential (LMP) tumors, or borderline ovarian tumors (BOTs), are a unique subtype of epithelial ovarian cancers (EOCs) that are the leading cause of death of gynecologic cancers and the fifth leading cause of all cancer-related deaths among women. To date, BOTs consist of disparate groups of neoplasms based on histopathological and molecular characteristics, as well as clinical behavior [1]. In 1929, Howard Taylor first found ovarian LMP tumors as a "semimalignant" disease between benign neoplasms and invasive carcinoma, regardless of clinical manifestations or histologic features [2]. In 1971, the International Federation of Obstetrics and Gynecology (FIGO) identified these "semimalignant" ovarian tumors as a "low-grade malignant tumor" totally different from ovarian cancer, and the word "borderline tumor" displaced "low-grade malignant tumor" in the World Health Organization (WHO) classification of female genital tumors in 2014 [3,4]. The BOT accounts for approximately 10 15\% of EOCs and usually occurs in younger women compared with generally common high-grade serous ovarian, tubal, and peritoneal cancers with a stepwise manner of progression from precursor lesions to invasive disease $[5,6]$. In recent decades, clear evidence has shown that the BOT does have intercalary biologic, histologic, pathogenetic, and molecular features intermediate between clearly benign and frankly malignant ovarian neoplasms, and BOTs are classified into serous borderline ovarian tumors (SBOTs), mucinous borderline ovarian tumors (MBOTs), seromucinous borderline tumors, endometrial borderline tumors, clear cell borderline tumors, transitional (Brenner) and other subtypes on the basis of histogenesis and histopathology in light of the recent 2014 WHO classification of tumors of female genital organs [4]. Generally, SBOTs, approximately $65 \%$ of BOTs [7], occur mostly in North America, the Middle East, and most of Europe. In contrast, MBOTs, approximately $32 \%$ of BOTs [8], occur predominately in East Asia and parts of Europe [9]. BOTs are predominantly diagnosed in premenopausal females before the age of 40 and are rarely confirmed in older women after the age of 65 [10-12].

BOTs, unlike invasive ovarian cancer, are chiefly diagnosed at an early stage $(75 \%$ of BOTs are diagnosed at stage I) and have more slothful clinical behavior, resulting in an excellent prognosis [13]. Generally, the 5-year overall survival rates of BOTs for stages I, II, and III are 99, 98, and 96\%, respectively, and the 10-year overall survival rates of BOTs for stages I, II, and III are 97, 90, and 88\%, respectively [14]. Nevertheless, some patients with BOTs under primary treatment may suffer from later symptomatic recurrence or malignant transformation resistant to platinum chemotherapy and death even after 20 years [15-17]. To date, surgery is still the major ideal method to treat BOTs. There are two standard surgical methods applied for removing macroscopically visible BOTs: a conservative operation for the young with a desire for fertility preservation or childbearing and radical surgery for the postmenopausal groups [18-20]. In addition, the method of surgery also depends on the histopathological characteristics of BOTs since there is always a risk of recurrence or development of invasive ovarian tumors [13,21,22]. Adjuvant chemotherapy and radiotherapy are not usually considered the standard therapy except surgical intervention because the 
role of adjuvant chemotherapy for BOTs is restricted [23-27], not to mention contentious radiational, hormonal, or targeted therapy in borderline ovarian tumors [21].

Because conventional chemotherapy demonstrated very limited activity in BOTs, some studies had started on molecular and gene mutations of BOTs early, hoping to find a more effective treatment for eradication after surgery. Recent studies have inferenced several assumptions, including the incessant ovulation hypothesis, gonadotropin hypothesis, hormonal hypothesis, and inflammation hypothesis, for the tumorigenesis of BOTs [28-31]. Earlier studies for BOTs and their first two most common subtypes, SBOT and MBOT, identified that mutations in the KRAS, $B R A F$, and $E R B B 2$ genes and overexpression of the p53 and Claudin-1 genes characterized SBOTs and that KRAS mutation, ERBB2 mutation or amplification, trefoil factor-3 (TFF3) strong expression, and HER-2/neu amplification accounted for a certain proportion of MBOT occurrence [17,32-37]. Therefore, detecting the status of $K R A S, E R B B 2, p 53$, or $B R A F$ mutation status may be a useful way to predict or investigate the possibility and tendency for the recurrence of BOTs or invasive ovarian carcinoma under satisfactory clinical scenarios. In addition to discovering the position of gene mutations, several preclinical studies have also clarified that several biomolecular activations of the mitogen-activated protein kinase (MAPK)/extracellular signal-regulated kinase (ERK) pathway, PI3K/AKT/mTOR pathway, Hedgehog pathway, and angiogenesis pathway take place in both SBOTs and MBOTs, with certain separate proportions that may appear as targeting subjects for innovative therapies [17,34,38-41]. As a result, clinical trials for low-grade serous carcinoma, mucinous carcinoma, and BOTs with targeted therapies focused on potential genes or pathways mentioned above have developed slowly and gradually in recent years, including MEK inhibitor (MEKi) therapy, agents targeting the $\mathrm{PI} 3 \mathrm{~K} / \mathrm{AKT} / \mathrm{mTOR}$ pathway, and antiangiogenic agents. However, all results of these targeted therapies are still pending to date due to extremely limited information and experience [42-44].

Although modern molecular studies, including analyses of mutational status, DNA copy number changes, and gene expression profiles, have provided initial insight into the pathogenesis of BOTs, there is still no integrative model for analyzing the comparison of genome profiles between BOTs, the more common SBOT, and the less common MBOT. To further understand the detailed information of the crucial deregulated biomolecular and genetic functions, we had previously organized integrated gene expression profiles downloaded from public databases and established a gene-based set regularity model based on the ordinal change among the gene elements in a gene set detected by microarrays to rebuild the gene set regularity (GSR) indices of the global functions and functionomes for measurement of the changes of the ordering levels of the gene elements defined by the gene ontology $(\mathrm{GO})$ gene sets definition. It could be utilized for investigating the meaningful dysregulated functions and dysfunctional pathway participating in complicated diseases such as ovarian carcinomas via comparison to differentially expressed genes (DEGs) [45-50]. Using these research methods, we conducted a genome-wide integrative investigation to analyze the global functions of BOTs at different subtypes by analyzing entire meaningful deregulated functions of BOTs detected by microarrays via concepts of the DEGs and rebuilt a functionome-pattern of a GSR model of the global functions to investigate further comprehensive data of the related, meaningful, neoplastic mechanisms and dysregulated functions accompanied by corresponding genes at different subtypes of BOTs, including mainly SBOTs and MBOTs. We could observe more clearly if there was significant functional pathogenic and biomolecular deterioration among all BOTs, SBOTs, and MBOTs by quantifying the general and further categorized functions under the structure of the GO-defined gene sets. The consequences of these analytics may be conducive to further specific investigation and advancement of precise therapy for BOTs in the future. 


\section{Results}

\subsection{Workflow for the Integrative Analyzing Model}

The workflow of this study is shown in Figure 1, and the minutiae of this algorithm are depicted in the Section 4. First, we transformed the extracted gene expression profiles of the gene elements to ordinal data and then to 10,192 quantified GO terms based on the sequence of expression from the gene elements in each gene set. This procedure generated functionomes consisting of 10,192 GSR indices, defining relatively comprehensive biological and molecular functions for investigating BOTs. Next, we calculated the quantified functions and the functional regularity patterns between 92 BOT samples and 136 normal ovarian controls with gene set regularity (GSR) indices and set up the GSR model of the functionome pattern. We then investigated the informativeness of the genome-wide functionome consisting of GSR indices and established a functionome-based training method for classification and prediction with the help of a set of supervised mathematical commands from machine learning, which is a support vector machine (SVM). The deregulated functions were detected by significant difference between BOT groups and normal controls, and the $p$-value was set at 0.05 . The variation in the GSR indices between each BOT group consisting of all BOTs, SBOTs, and MBPTs and normal controls indicated that the biomolecular functions were widely dysregulated in the BOT groups compared with the normal controls with statistical significance. Finally, we performed a whole-genome integrative analysis to identify meaningful dysfunctional pathways and potential DEGs and possible essential parts of the pathogenesis of BOTs by discovering the dysregulated biomolecular and genetic functions of BOTs detected by microarrays with gene expression profiles. The crucial biological functions and genes involved in the pathogenesis of BOTs were detected by investigating genome-wide GO-defined functions and DEGs.

\subsection{Microarray Gene Expression Datasets and Gene Set Definition}

We used the integrative method of gene ontology-based analysis to investigate all related dysregulated functions of BOTs. DNA microarray gene expression datasets were downloaded from the National Center for Biotechnology Information (NCBI) Gene Expression Omnibus (GEO) database, and the sample data were obtained from 28 dataset series containing six different DNA microarray platforms without any missing data. A total of 92 BOT samples were collected, including 79 samples of SBOT and 13 samples of MBOT in terms of histological classification (Table 1); 35 samples of stage I, five samples of stage II, ten samples of stage III, one sample of stages IV, and 41 samples of unconfirmed stages in terms of the International Federation of Gynecology and Obstetrics (FIGO) staging system. For comparison, 136 normal ovarian samples were gathered as a control group. Detailed information of all collected samples is available in Table S1. The 10,192 GO gene set definitions for annotation of all functions were downloaded from the Molecular Signatures Database (MSigDB) with the version "c5.all.v7.1.symbols.gmt" [51].

Table 1. Number of samples and statistics of gene set regularity indices for the BOT, serous BOT (SBOT), and mucinous BOT (MBOT) groups.

\begin{tabular}{ccccccc}
\hline Groups & Sample & Control & Total & Sample Mean (SD $\left.{ }^{\mathbf{1}}\right)$ & Control Mean (SD $^{\mathbf{1}}$ ) & $\boldsymbol{p}_{\text {-Value }}$ \\
\hline All BOTs & 92 & 136 & 228 & $0.6689(0.1892)$ & $0.7731(0.1647)$ & $<0.05$ \\
SBOT (Serous) & 79 & 136 & 215 & $0.7036(0.1772)$ & $0.7732(0.1646)$ & $<0.05$ \\
MBOT (Mucinous) & 13 & 136 & 149 & $0.5032(0.1590)$ & $0.7731(0.1643)$ & $<0.05$ \\
\hline
\end{tabular}

\footnotetext{
${ }^{1} \mathrm{SD}$, standard deviation.
} 


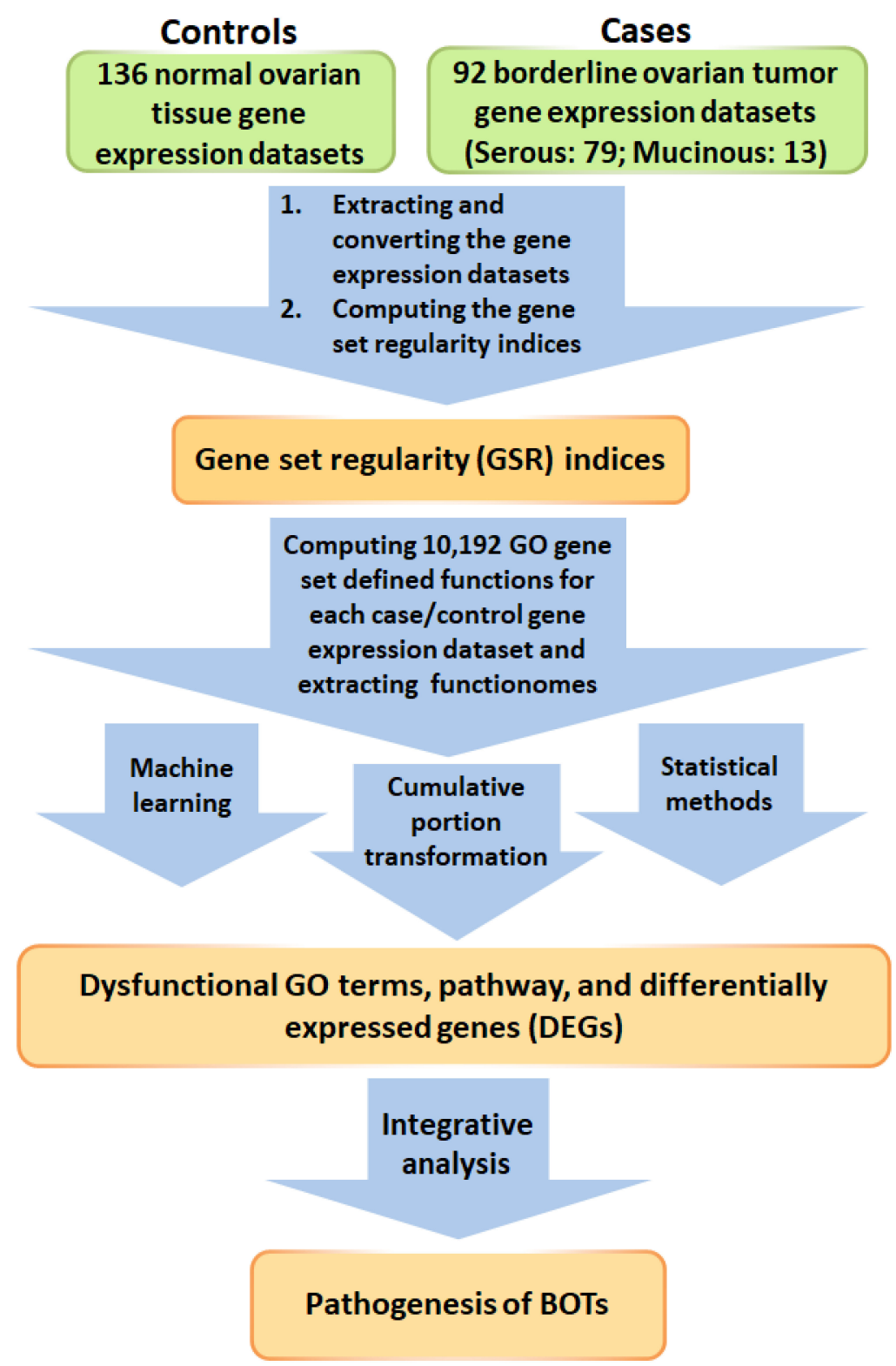

Figure 1. Workflow of this study. The DNA microarray gene expression datasets of 92 borderline ovarian tumor (BOT) samples and 136 normal ovarian controls were downloaded from a publicly available database with the gene set regularity (GSR) index calculated by the Gene Ontology (GO) gene set. Functionomes consisting of 10,192 GO gene sets established from the polygenic model and machine learning with statistical methods and cumulative portion transformations were used to recognize the functionome patterns to discover dysfunctional GO terms, pathways, and differentially expressed genes (DEGs). Finally, the pathogenesis of BOTs was investigated by integrative analysis.

\subsection{Means and Histograms of GSR Indices of Functionomes among Each BOT Sample Group with} Different Divergences

We calculated the means of the GSR indices of functionomes for all BOTs, serous BOTs (SBOTs), and mucinous BOTs (MBOTs), corrected by the averages from the control groups, as shown in Figure 2. The GSR index delineated by quantified changes in the gene expression ranking in a gene set was computed based on the extent of ranking change within a gene set defined by the GO terms or biological canonical pathways between the case and control groups, and the variations in GSR indices between each case and the normal control group were statistically significant $(p<0.05)$, which revealed notably decreased deviations among all BOT groups (orange lattice in Figure 2A), SBOTs 
(orange lattice in Figure 2B), and MBOTs (orange lattice in Figure 2C), indicating the steady deterioration of functional regulation of BOTs apart from normal controls (blue lattice in Figure 2). More obvious deviation in MBOTs distinct from SBOTs indicated more irregular changes of dysregulated function. Quantifying the regulation of dysregulated functions by surveying the average of the total GSR indices among each functionome, with subsequent corrections based on the control groups, the numerical average values of the corrected GSR indices for all BOTs, SBOTs, and MBOTs were $0.6689,0.7036$, and 0.5032 , respectively.

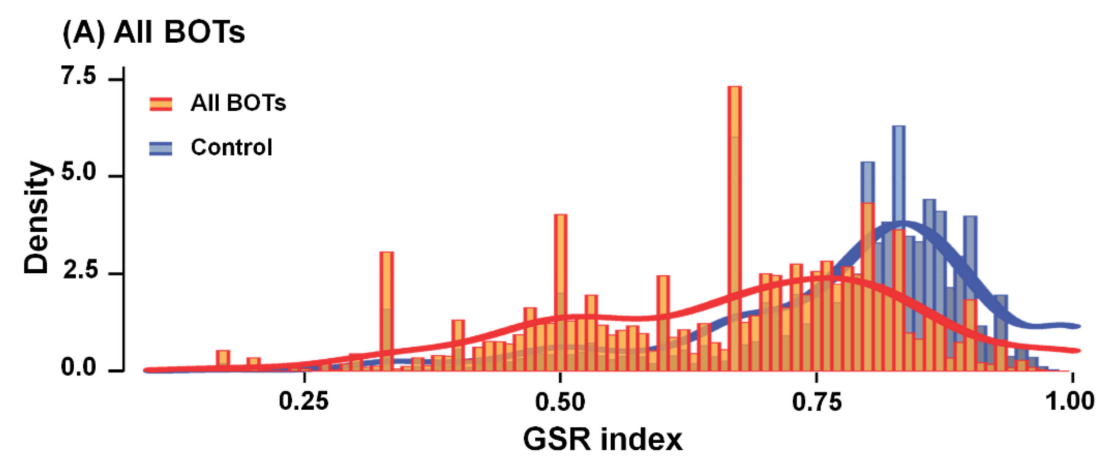

\section{(B) Serous BOT}

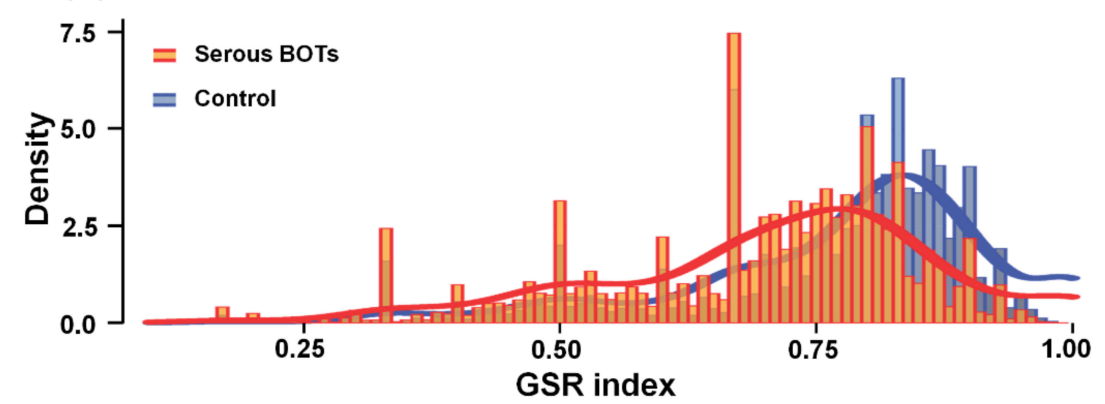

(C) Mucinous BOT

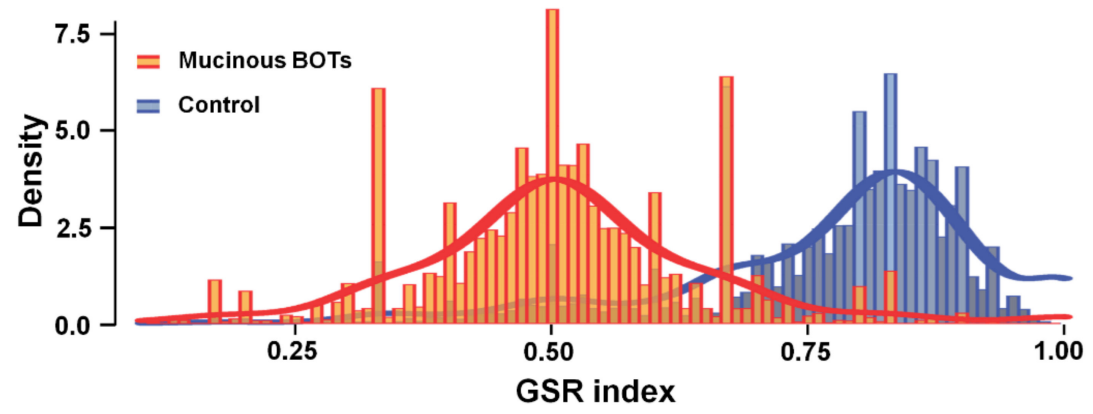

Figure 2. Histograms of global GSR indices of functionomes among all BOTs (serous BOTs and mucinous BOTs (orange) and control groups (blue)): These figures reveal different distributions of the functionomes for three case sample groups and control group's statistical significance $(p<0.05)$. The normal control group (blue) located on the right side of the histogram was the same for the three case groups and used as the controls. A second peak of distribution was observed (orange), indicating deregulated biomolecular functions among all BOTs, SBOTs, and MBOTs. (A) Corrected GSR indices of all BOTs: 0.6689; (B) corrected GSR indices of serous BOTs: 0.7036; and (C) corrected GSR indices of mucinous BOTs: 0.5032 .

\subsection{Global Functional Regularity Patterns Predicted and Classified by Machine Learning with High Accuracies}

As the histograms show above, there were indeed significant differences in functional regularity patterns among the three case groups (all BOTs, SBOTs, and MBOTs) from the normal control group. With the help of supervised machine learning, we used a support 
vector machine (SVM) technological algorithm to recognize, classify, and predict distinct functionomes with GSR indices. The performance was evaluated with binary classification and inspected by fivefold cross-validation. The cumulative performance results are listed in Table 2 with the averages of ten continuous classifications and predictions. The accuracies of binary classification (case vs. control) ranged from $99.77 \%$ to $100.00 \%$. The classification between the MBOT and normal control groups had the best results. The areas under the curve (AUCs) of the test for each case group ranged from 0.9967 to 1.0000. These results with high accuracies indicated that the functional regularity patterns quantified by the GSR indices converted from the microarray gene expression profiles can provide adequate informative data for the SVM to perform correct recognition and classification. The results also revealed that the functional regularity patterns among all BOTs, SBOTs, and MBOTs were distinct and could be utilized for the molecular classification of the gene expression profiles among each case group.

Table 2. Accuracies of binary classification and prediction by machine learning.

\begin{tabular}{ccccccc}
\hline Gene Set & Classification & Group & Sensitivity $\left(\right.$ SD $\left.^{\mathbf{1}}\right)$ & Specificity (SD $\left.^{\mathbf{1}}\right)$ & Accuracy $_{\left(\text {SD }^{\mathbf{1}}\right)}$ & AUC $^{\mathbf{2}}$ \\
\hline \multirow{3}{*}{ GO term } & \multirow{3}{*}{ Binary } & All BOTs & $0.9944(0.01757)$ & $1.0000(0.0000)$ & $0.9978(0.0069)$ & 0.9974 \\
& & SBOT $^{3}$ & $0.9933(0.02108)$ & $1.0000(0.0000)$ & $0.9977(0.0074)$ & 0.9967 \\
& & MBOT $^{4}$ & $1.0000(0.0000)$ & $1.0000(0.0000)$ & $1.0000(0.0000)$ & 1.0000 \\
\hline
\end{tabular}

${ }^{1} \mathrm{SD}$, standard deviation; ${ }^{2} \mathrm{AUC}$, area under curve; ${ }^{3} \mathrm{SBOT}$, serous BOT; ${ }^{4} \mathrm{MBOT}$, Mucinous BOT.

\subsection{The Most Deregulated and Common Gene Ontology (GO) Terms of BOTs and Subtypes}

There were 717, 655, and $792 \mathrm{GO}$ terms among all BOT, SBOT, and MOBT groups, respectively, summarized and ranked by cluster weight index (CWI), which was a measured index of a weighed ratio based on the $p$-values for each clustered deregulated GO term with statistical significance. CWI was defined as the ratio of that cluster weight divided by the sum weight of total clusters to measure the weight and to represent the relevance of each cluster in the GO tree, and we used CWI calculated to quantify and evaluate the importance of each GO cluster in the pathogenesis of BOTs. A higher CWI indicates higher relevance and importance. The 50 most deregulated GO terms ranked by CWI for all BOTs, SBOTs, and MBOTs are displayed in Table 3. The first deregulated GO term for each stage group was "regulation of immune system process (GO:0002682)" for all BOTs, "regulation of immune system process (GO:0002682)" for SBOTs, and "small molecule metabolic process (GO:0044281)" for MBOTs. Then, we summarized and rearranged the top 41 GO terms in order that appeared repeatedly in the 50 most deregulated GO terms among the three groups according to the weighted CWI proportions in each group, as shown in Table 4 with their original ranking in each group. We then traced and compared the trends of ranking order of the top 41 common deregulated GO terms for each group to evaluate the importance of a given functionome among all BOTs, SBOTs, and MBOTs. The ranking trend distributions of deregulated $\mathrm{GO}$ terms for all $\mathrm{BOTs}$, SBOTs, and MBOTs are shown in Figure 3 and the whole deregulated GO terms of all BOTs, SBOTs, and MBOTs are listed in detail in Table S2. We found obviously that the ranking orders and trends of these top 41 common deregulated GO terms of all BOTs and SBOTs were the same in the majority, and the ranking trend distribution of the deregulated GO terms of MBOTs did not go congruously with all BOTs and SBOTs. Next, all top 41 common deregulated GO terms among the three case groups could be classified based on the functions they represent and organized into the following categories: immune and inflammatory response-related functions, cell membrane and transporter related functions, cell cycle and signaling related functions, cell metabolism related functions, and others that are not classified into the above four categories. 
Table 3. The 50 most deregulated GO terms for all BOTs, SBOTs, and MBOTs ranked by CWI (cluster weight index).

\begin{tabular}{|c|c|c|c|c|c|c|c|c|c|}
\hline \multirow{2}{*}{$\begin{array}{l}\text { Category } \\
\text { Ranking }\end{array}$} & \multicolumn{3}{|c|}{ All BOTs } & \multicolumn{3}{|c|}{ Serous BOTs } & \multicolumn{3}{|c|}{ Mucinous BOTs } \\
\hline & GO ID & GO Term & CWI & GO ID & GO Term & CWI & GO ID & GO Term & CWI \\
\hline 1 & GO:0002682 & $\begin{array}{l}\text { Regulation of immune } \\
\text { system process }\end{array}$ & 0.02426 & GO:0002682 & $\begin{array}{l}\text { Regulation of immune } \\
\text { system process }\end{array}$ & 0.0255 & GO:0044281 & $\begin{array}{l}\text { Small molecule } \\
\text { metabolic process }\end{array}$ & 0.01957 \\
\hline 2 & GO:0001775 & Cell activation & 0.01783 & GO:0005215 & Transporter activity & 0.02032 & GO:0002682 & $\begin{array}{l}\text { Regulation of immune } \\
\text { system process }\end{array}$ & 0.01772 \\
\hline 3 & GO:0005215 & Transporter activity & 0.01737 & GO:0001775 & Cell activation & 0.02015 & GO:0051049 & $\begin{array}{l}\text { Regulation of } \\
\text { transport }\end{array}$ & 0.01434 \\
\hline 4 & GO:0006811 & Ion transport & 0.01678 & GO:0006811 & Ion transport & 0.01765 & GO:0006811 & Ion transport & 0.01187 \\
\hline 5 & GO:0044281 & $\begin{array}{l}\text { Small molecule metabolic } \\
\text { process }\end{array}$ & 0.01622 & GO:0044281 & $\begin{array}{c}\text { Small molecule metabolic } \\
\text { process }\end{array}$ & 0.01653 & GO:0045595 & $\begin{array}{l}\text { Regulation of cell } \\
\text { differentiation }\end{array}$ & 0.01145 \\
\hline 6 & GO:0051049 & Regulation of transport & 0.01345 & GO:0051049 & Regulation of transport & 0.01324 & GO:0006629 & $\begin{array}{l}\text { Lipid metabolic } \\
\text { process }\end{array}$ & 0.01135 \\
\hline 7 & GO:0002252 & Immune effector process & 0.01313 & GO:0002252 & Immune effector process & 0.0131 & GO:0001775 & Cell activation & 0.01114 \\
\hline 8 & GO:0001816 & Cytokine production & 0.01255 & GO:0002520 & $\begin{array}{c}\text { Immune system } \\
\text { development }\end{array}$ & 0.01284 & GO:0016070 & $\begin{array}{l}\text { RNA metabolic } \\
\text { process }\end{array}$ & 0.01101 \\
\hline 9 & GO:0002520 & $\begin{array}{c}\text { Immune system } \\
\text { development }\end{array}$ & 0.01219 & GO:0001816 & Cytokine production & 0.01252 & GO:0005215 & Transporter activity & 0.01008 \\
\hline 10 & GO:0045595 & $\begin{array}{l}\text { Regulation of cell } \\
\text { differentiation }\end{array}$ & 0.01147 & GO:0045595 & $\begin{array}{l}\text { Regulation of cell } \\
\text { differentiation }\end{array}$ & 0.01129 & GO:0001816 & Cytokine production & 0.00999 \\
\hline 11 & GO:0006629 & Lipid metabolic process & 0.01013 & GO:0031399 & $\begin{array}{l}\text { Regulation of protein } \\
\text { modification process }\end{array}$ & 0.01021 & GO:0022008 & Neurogenesis & 0.00984 \\
\hline 12 & GO:0040011 & Locomotion & 0.0094 & GO:0006629 & Lipid metabolic process & 0.01018 & GO:0040011 & Locomotion & 0.00954 \\
\hline 13 & GO:0031399 & $\begin{array}{l}\text { Regulation of protein } \\
\text { modification process }\end{array}$ & 0.00929 & GO:0048585 & $\begin{array}{l}\text { Negative regulation of } \\
\text { response to stimulus }\end{array}$ & 0.00945 & GO:0002520 & $\begin{array}{c}\text { Immune system } \\
\text { development }\end{array}$ & 0.00947 \\
\hline 14 & GO:0042592 & Homeostatic process & 0.00925 & GO:0042592 & Homeostatic process & 0.00939 & GO:0007267 & Cell-cell signaling & 0.00906 \\
\hline
\end{tabular}


Table 3. Cont.

\begin{tabular}{|c|c|c|c|c|c|c|c|c|c|}
\hline \multirow{2}{*}{$\begin{array}{l}\text { Category } \\
\text { Ranking }\end{array}$} & \multicolumn{3}{|c|}{ All BOTs } & \multicolumn{3}{|c|}{ Serous BOTs } & \multicolumn{3}{|c|}{ Mucinous BOTs } \\
\hline & GO ID & GO Term & CWI & GO ID & GO Term & CWI & GO ID & GO Term & CWI \\
\hline 15 & GO:0046903 & Secretion & 0.00922 & GO:0022610 & Biological adhesion & 0.00926 & GO:0042592 & Homeostatic process & 0.00884 \\
\hline 17 & GO:0051240 & $\begin{array}{l}\text { Positive regulation of } \\
\text { multicellular organismal } \\
\text { process }\end{array}$ & 0.00891 & GO:0051240 & $\begin{array}{l}\text { Positive regulation of } \\
\text { multicellular organismal } \\
\text { process }\end{array}$ & 0.00904 & GO:0051240 & $\begin{array}{c}\text { Positive regulation of } \\
\text { multicellular } \\
\text { organismal process }\end{array}$ & 0.00867 \\
\hline 18 & GO:0048585 & $\begin{array}{l}\text { Negative regulation of } \\
\text { response to stimulus }\end{array}$ & 0.00886 & GO:0006915 & Apoptotic process & 0.00902 & GO:0019219 & $\begin{array}{c}\text { Regulation of } \\
\text { nucleobase-containing } \\
\text { compound metabolic } \\
\text { process }\end{array}$ & 0.00864 \\
\hline 19 & GO:0022610 & Biological adhesion & 0.00873 & GO:0046903 & Secretion & 0.00887 & GO:0046903 & Secretion & 0.00858 \\
\hline 20 & GO:0016070 & RNA metabolic process & 0.00861 & GO:0060429 & Epithelium development & 0.00875 & GO:0060429 & $\begin{array}{c}\text { Epithelium } \\
\text { development }\end{array}$ & 0.00854 \\
\hline 21 & GO:0006915 & Apoptotic process & 0.00859 & GO:0051174 & $\begin{array}{l}\text { Regulation of phosphorus } \\
\text { metabolic process }\end{array}$ & 0.00867 & GO:0002252 & $\begin{array}{l}\text { Immune effector } \\
\text { process }\end{array}$ & 0.00826 \\
\hline 22 & GO:0051276 & Chromosome organization & 0.00839 & GO:0051276 & Chromosome organization & 0.00866 & GO:0033043 & $\begin{array}{c}\text { Regulation of } \\
\text { organelle organization }\end{array}$ & 0.00808 \\
\hline 23 & GO:0055085 & Transmembrane transport & 0.00818 & GO:0007267 & Cell-cell signaling & 0.00846 & GO:0006259 & $\begin{array}{l}\text { DNA metabolic } \\
\text { process }\end{array}$ & 0.00774 \\
\hline 24 & GO:0060429 & Epithelium development & 0.00807 & GO:0007049 & Cell cycle & 0.0082 & GO:0031399 & $\begin{array}{l}\text { Regulation of protein } \\
\text { modification process }\end{array}$ & 0.00767 \\
\hline 25 & GO:0007049 & Cell cycle & 0.00787 & GO:0070727 & $\begin{array}{c}\text { Cellular macromolecule } \\
\text { localization }\end{array}$ & 0.008 & GO:0000003 & Reproduction & 0.00742 \\
\hline 26 & GO:0051174 & $\begin{array}{l}\text { Regulation of phosphorus } \\
\text { metabolic process }\end{array}$ & 0.00779 & GO:0016070 & RNA metabolic process & 0.00799 & GO:0006915 & Apoptotic process & 0.00733 \\
\hline
\end{tabular}


Table 3. Cont.

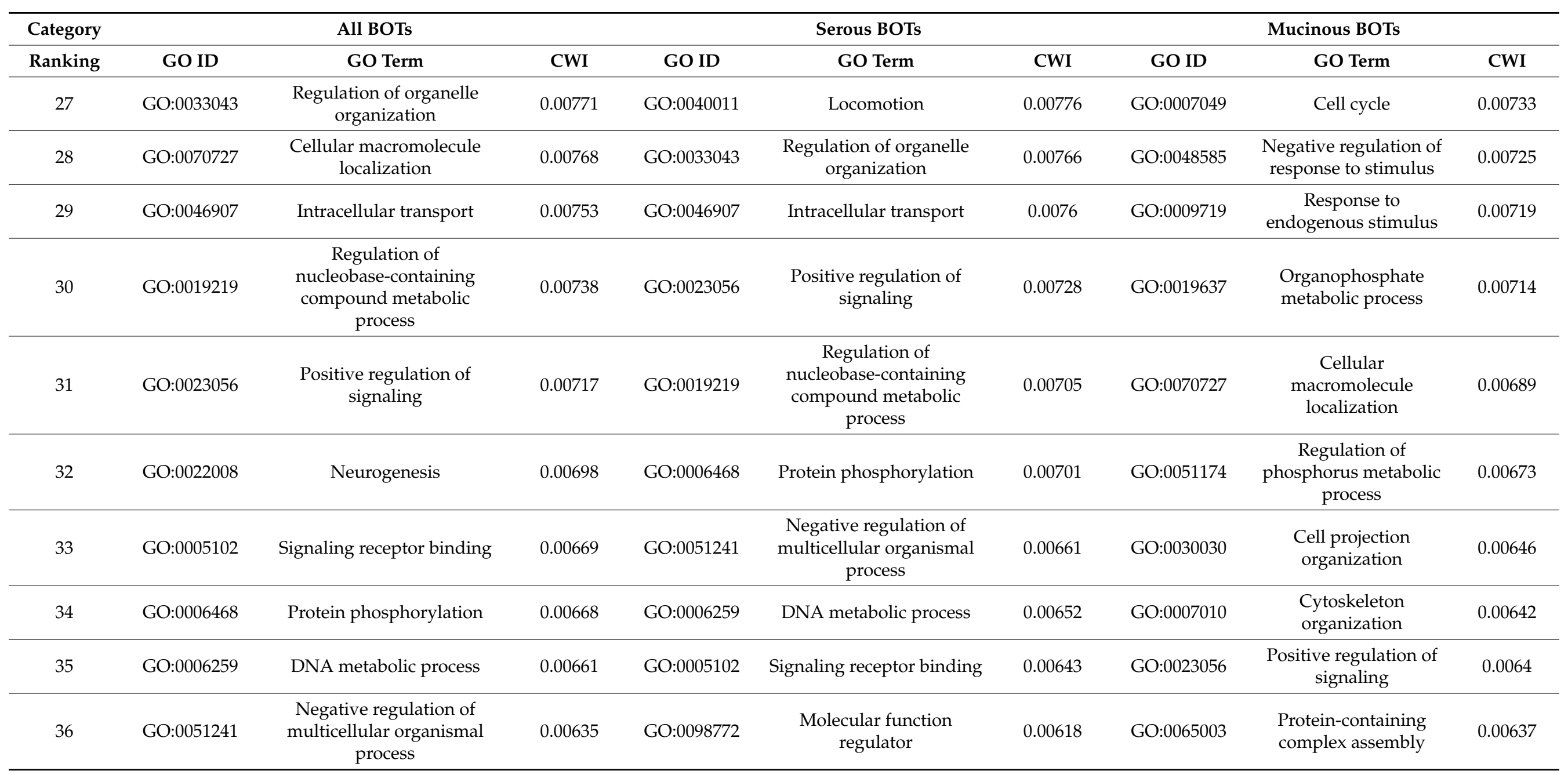


Table 3. Cont.

\begin{tabular}{|c|c|c|c|c|c|c|c|c|c|}
\hline \multirow{2}{*}{$\begin{array}{l}\text { Category } \\
\text { Ranking }\end{array}$} & \multicolumn{3}{|c|}{ All BOTs } & \multicolumn{3}{|c|}{ Serous BOTs } & \multicolumn{3}{|c|}{ Mucinous BOTs } \\
\hline & GO ID & GO Term & CWI & GO ID & GO Term & CWI & GO ID & GO Term & CWI \\
\hline 37 & GO:0044419 & $\begin{array}{l}\text { Interspecies interaction } \\
\text { between organisms }\end{array}$ & 0.00635 & GO:0080134 & $\begin{array}{c}\text { Regulation of response to } \\
\text { stress }\end{array}$ & 0.00617 & GO:0007417 & $\begin{array}{c}\text { Central nervous } \\
\text { system development }\end{array}$ & 0.00628 \\
\hline 38 & GO:0098772 & $\begin{array}{l}\text { Molecular function } \\
\text { regulator }\end{array}$ & 0.00617 & GO:0022008 & Neurogenesis & 0.00604 & GO:0051241 & $\begin{array}{c}\text { Negative regulation of } \\
\text { multicellular } \\
\text { organismal process }\end{array}$ & 0.00625 \\
\hline 39 & GO:0015849 & Organic acid transport & 0.00597 & GO:0015849 & Organic acid transport & 0.00597 & GO:0046907 & Intracellular transport & 0.00607 \\
\hline 40 & GO:0080134 & $\begin{array}{c}\text { Regulation of response to } \\
\text { stress }\end{array}$ & 0.00592 & GO:0044419 & $\begin{array}{l}\text { Interspecies interaction } \\
\text { between organisms }\end{array}$ & 0.00593 & GO:0018193 & $\begin{array}{l}\text { Peptidyl-amino acid } \\
\text { modification }\end{array}$ & 0.00591 \\
\hline 41 & GO:0009719 & $\begin{array}{l}\text { Response to endogenous } \\
\text { stimulus }\end{array}$ & 0.00578 & GO:0023057 & $\begin{array}{c}\text { Negative regulation of } \\
\text { signaling }\end{array}$ & 0.00589 & GO:0055085 & $\begin{array}{l}\text { Transmembrane } \\
\text { transport }\end{array}$ & 0.00572 \\
\hline 42 & GO:0002250 & Adaptive immune response & 0.00577 & GO:0010941 & Regulation of cell death & 0.00588 & GO:0080134 & $\begin{array}{c}\text { Regulation of response } \\
\text { to stress }\end{array}$ & 0.00564 \\
\hline 43 & GO:0000003 & Reproduction & 0.00571 & GO:0042127 & $\begin{array}{l}\text { Regulation of cell } \\
\text { proliferation }\end{array}$ & 0.00583 & GO:0005102 & $\begin{array}{l}\text { Signaling receptor } \\
\text { binding }\end{array}$ & 0.00558 \\
\hline 45 & GO:0023057 & $\begin{array}{c}\text { Negative regulation of } \\
\text { signaling }\end{array}$ & 0.00564 & GO:0002250 & Adaptive immune response & 0.00579 & GO:0022610 & Biological adhesion & 0.00552 \\
\hline 46 & GO:0030030 & Cell projection organization & 0.00557 & GO:0019637 & $\begin{array}{l}\text { Organophosphate } \\
\text { metabolic process }\end{array}$ & 0.00557 & GO:0044419 & $\begin{array}{l}\text { Interspecies interaction } \\
\text { between organisms }\end{array}$ & 0.00543 \\
\hline 47 & GO:0042127 & $\begin{array}{l}\text { Regulation of cell } \\
\text { proliferation }\end{array}$ & 0.00556 & GO:0018193 & $\begin{array}{l}\text { Peptidyl-amino acid } \\
\text { modification }\end{array}$ & 0.00552 & GO:0006468 & $\begin{array}{c}\text { Protein } \\
\text { phosphorylation }\end{array}$ & 0.0054 \\
\hline 48 & GO:0019637 & $\begin{array}{c}\text { Organophosphate metabolic } \\
\text { process }\end{array}$ & 0.00554 & GO:0009628 & $\begin{array}{c}\text { Response to abiotic } \\
\text { stimulus }\end{array}$ & 0.00545 & GO:0016788 & $\begin{array}{l}\text { Hydrolase activity, } \\
\text { acting on ester bonds }\end{array}$ & 0.00525 \\
\hline 50 & GO:0065003 & $\begin{array}{l}\text { Protein-containing complex } \\
\text { assembly }\end{array}$ & 0.00544 & GO:0000003 & Reproduction & 0.00539 & GO:0009790 & Embryo development & 0.0052 \\
\hline
\end{tabular}


Table 4. The top 41 common deregulated GO terms among the three case groups (all BOTs, SBOTs, and MBOTs).

\begin{tabular}{|c|c|c|c|c|c|c|c|c|c|c|c|}
\hline Order & GO ID & GO Term & $\mathbf{B}^{1}$ & $\mathrm{~S}^{2}$ & $\mathbf{M}^{3}$ & Order & GO ID & GO Term & $\mathbf{B}^{1}$ & $S^{2}$ & $\mathbf{M}^{3}$ \\
\hline 1 & GO:0002682 & Regulation of immune system process & 1 & 1 & 2 & 21 & GO:0060429 & Epithelium development & 24 & 20 & 20 \\
\hline 2 & GO:0044281 & Small molecule metabolic process & 5 & 5 & 1 & 22 & GO:0006915 & Apoptotic process & 21 & 18 & 26 \\
\hline 3 & GO:0001775 & Cell activation & 2 & 3 & 7 & 23 & GO:0007049 & Cell cycle & 25 & 24 & 27 \\
\hline 4 & GO:0006811 & Ion transport & 4 & 4 & 4 & 24 & GO:0033043 & Regulation of organelle organization & 27 & 28 & 22 \\
\hline 5 & GO:0005215 & Transporter activity & 3 & 2 & 9 & 25 & GO:0022610 & Biological adhesion & 19 & 15 & 45 \\
\hline 6 & GO:0051049 & Regulation of transport & 6 & 6 & 3 & 26 & GO:0051174 & Regulation of phosphorus metabolic process & 26 & 21 & 32 \\
\hline 7 & GO:0045595 & Regulation of cell differentiation & 10 & 10 & 5 & 27 & GO:0019219 & $\begin{array}{l}\text { Regulation of nucleobase-containing } \\
\text { compound metabolic process }\end{array}$ & 30 & 31 & 18 \\
\hline 8 & GO:0001816 & Cytokine production & 9 & 9 & 10 & 28 & GO:0055085 & Transmembrane transport & 23 & 16 & 41 \\
\hline 9 & GO:0002520 & Immune system development & 8 & 8 & 13 & 29 & GO:0022008 & Neurogenesis & 32 & 38 & 11 \\
\hline 10 & GO:0006629 & Lipid metabolic process & 11 & 12 & 6 & 30 & GO:0070727 & Cellular macromolecule localization & 28 & 25 & 31 \\
\hline 11 & GO:0002252 & Immune effector process & 7 & 7 & 21 & 31 & GO:0006259 & DNA metabolic process & 35 & 34 & 23 \\
\hline 12 & GO:0042592 & Homeostatic process & 14 & 14 & 15 & 32 & GO:0023056 & Positive regulation of signaling & 31 & 30 & 35 \\
\hline 14 & GO:0040011 & Locomotion & 12 & 27 & 12 & 34 & GO:0051241 & $\begin{array}{l}\text { Negative regulation of multicellular } \\
\text { organismal process }\end{array}$ & 36 & 33 & 38 \\
\hline 15 & GO:0051240 & $\begin{array}{l}\text { Positive regulation of multicellular } \\
\text { organismal process }\end{array}$ & 17 & 17 & 17 & 35 & GO:0005102 & Signaling receptor binding & 33 & 35 & 43 \\
\hline 16 & GO:0046903 & Secretion & 15 & 19 & 19 & 36 & GO:0006468 & Protein phosphorylation & 34 & 32 & 47 \\
\hline 17 & GO:0007267 & Cell-cell signaling & 16 & 23 & 14 & 37 & GO:0000003 & Reproduction & 43 & 49 & 25 \\
\hline 18 & GO:0016070 & RNA metabolic process & 20 & 26 & 8 & 38 & GO:0080134 & Regulation of response to stress & 40 & 37 & 42 \\
\hline 19 & GO:0048585 & Negative regulation of response to stimulus & 18 & 13 & 28 & 39 & GO:0009719 & Response to endogenous stimulus & 41 & 50 & 29 \\
\hline \multirow[t]{2}{*}{20} & GO:0051276 & Chromosome organization & 22 & 22 & 16 & 40 & GO:0044419 & Interspecies interaction between organisms & 37 & 40 & 46 \\
\hline & & & & & & 41 & GO:0018193 & Peptidyl-amino acid modification & 44 & 47 & 40 \\
\hline
\end{tabular}

${ }^{1} \mathrm{~B}$, Ranking in all BOTs; ${ }^{2} \mathrm{~S}$, Ranking in SBOTs; ${ }^{3} \mathrm{M}$, Ranking in MBOTs. 
A

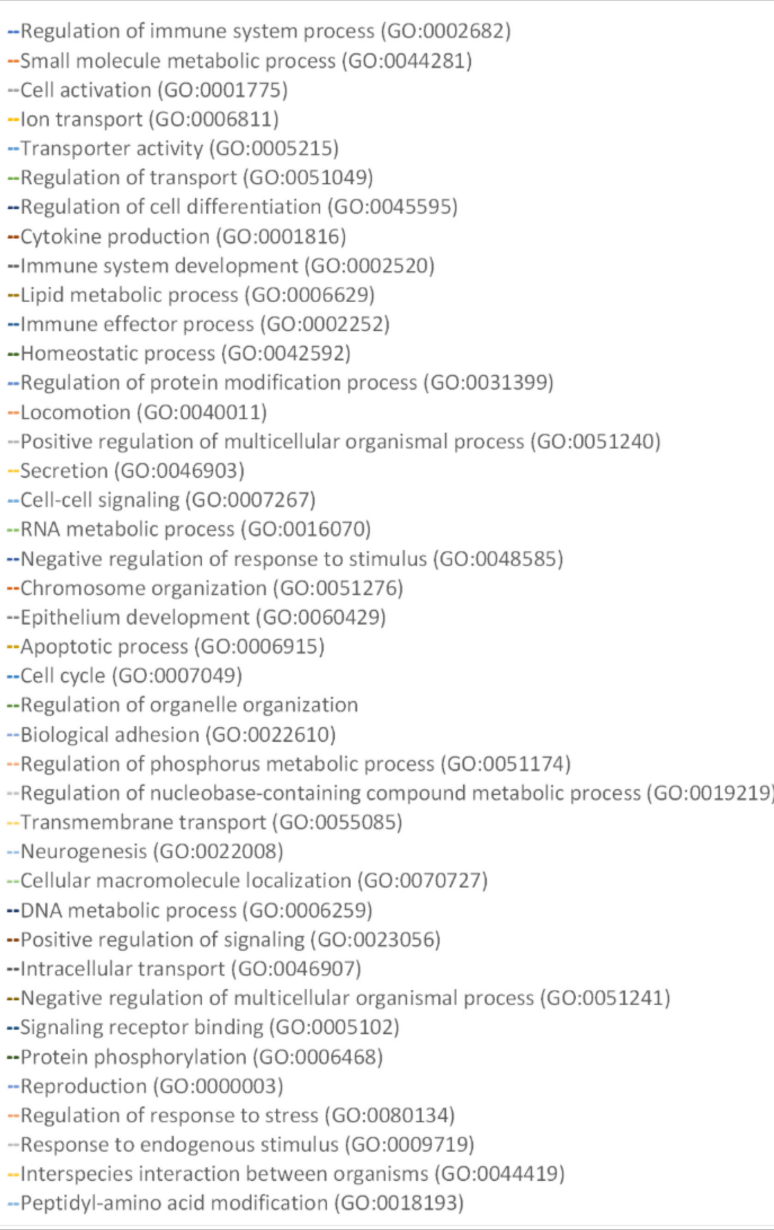

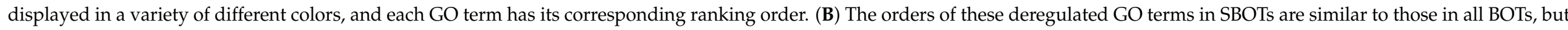
the orders in MBOTs are very inconsistent with those of all BOTs and SBOTs.

\section{B}
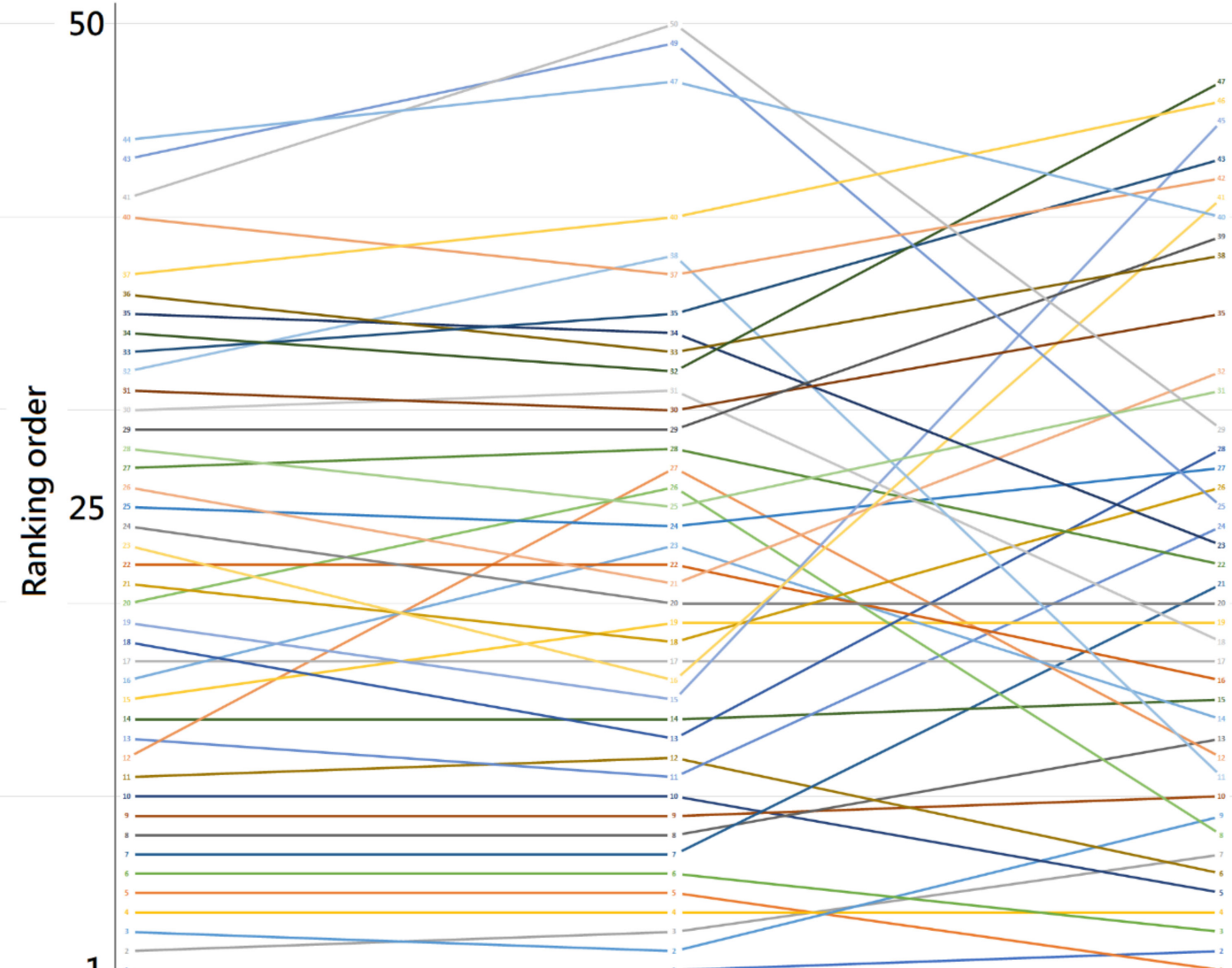

Ranking in SBOT

\section{Ranking in all BOTs}

Ranking in MBOT 


\subsection{Immune and Inflammatory Response-Related Functions and Relevant DEGs}

There were three GO terms among all BOT, SBOT, and MBOT groups classified into immune and inflammatory response-related functions: "regulation of immune system process (GO:0002682)", "immune system development (GO:0002520)", and "immune effector process (GO:0002252)"; the rankings of these immune-related GO terms in all groups were very much in front order. Each GO term, whether its representative cellular component, molecular function, or biological process, has a corresponding genome that annotates genes and gene products to enable functional interpretation of experimental data [52]. We utilized statistical methods to discover the potential genes from the genes with the definition of GO gene sets (http:/ / geneontology.org/, accessed on 15 April 2021) annotated for the above three GO terms and then intersected the DEGs calculated separately to find the relevant DEGs with the highest repetition. We found that the two DEGs: IL6 (interleukin 6) and CCR2 (C-C motif chemokine receptor 2) had the most frequent occurrence. The trends of ranking orders for each categorized GO term are shown in Figure 4 with detailed information.

\section{Immune and inflammatory response related functions}

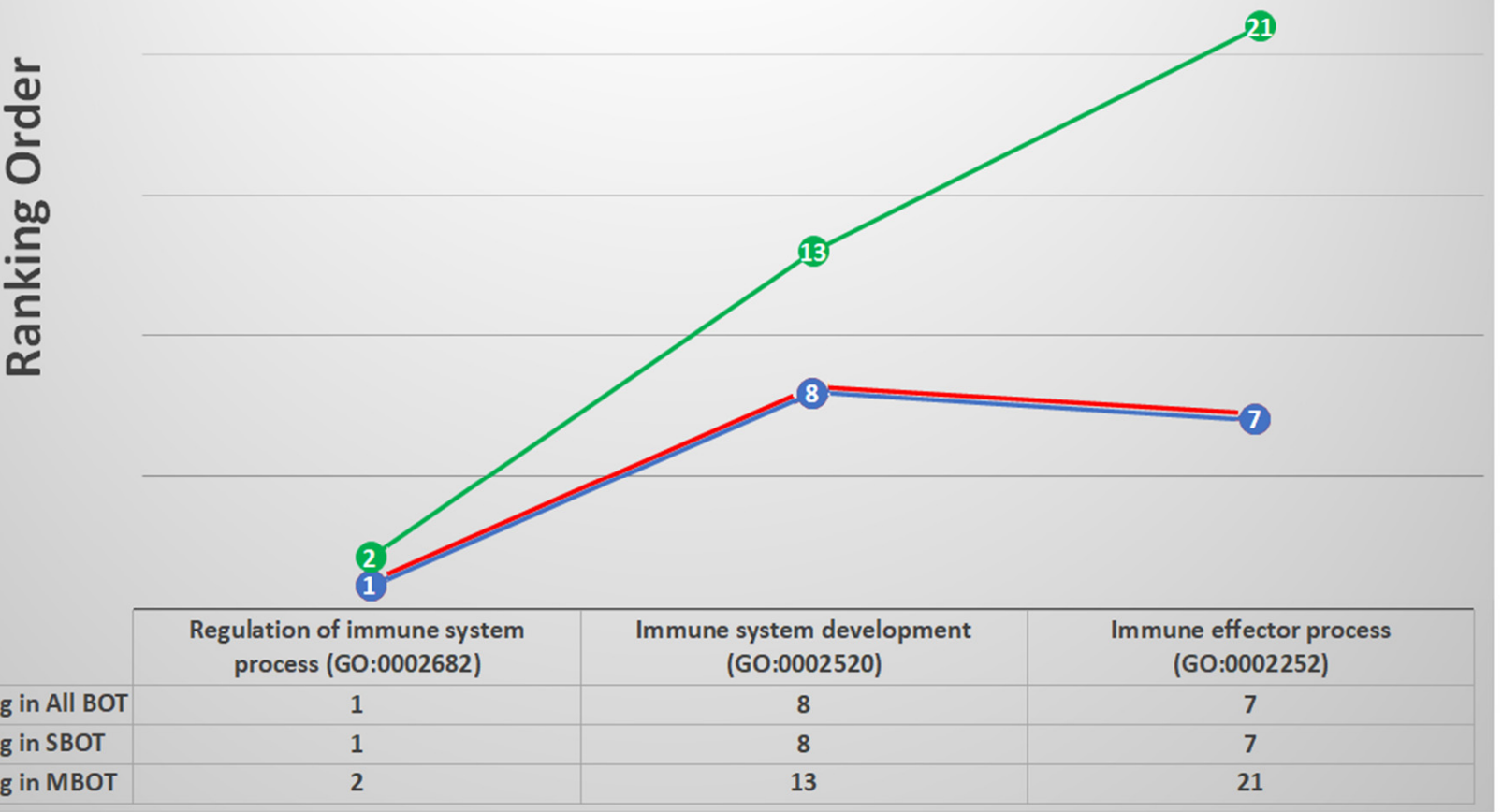

Immune and Inflammatory Response-Related Functions

Most Relevant DEGs: IL6, CCR2

\begin{tabular}{cccccc}
\hline Order & GO ID & GO Term & Ranking in All BOTs & Ranking in SBOT & Ranking in MBOT \\
\hline $\mathbf{1}$ & GO:0002682 & $\begin{array}{c}\text { Regulation of immune system } \\
\text { process }\end{array}$ & 1 & 1 & 2 \\
\hline $\mathbf{9}$ & GO:0002520 & Immune system development & 8 & 8 & 13 \\
\hline $\mathbf{1 1}$ & GO:0002252 & Immune effector process & 7 & 7 & 21 \\
\hline
\end{tabular}

Figure 4. The trends and list with ranking orders of three deregulated GO terms classified into immune and inflammatory response-related functions and the two most relevant DEGs with calculations and comparison. 


\subsection{Cell Membrane- and Transporter-Related Functions and Relevant DEGs}

Similarly, based on the annotated biological functions, nine GO terms among three disease groups were categorized as cell membrane- and transporter response-related functions: "ion transport (GO:0006811)", "transporter activity (GO:0005215)", "regulation of transport (GO:0051049)", "locomotion (GO:0040011)", "secretion (GO:0046903)", "biological adhesion (GO:0022610)", "transmembrane transport (GO:0055085)", "cellular macromolecule localization (GO:0070727)", and "intracellular transport (GO:0046907)"; the ranking orders and trends of these clustered GO terms are revealed in Figure 5 in detail. We also used the calculation method to identify the potential genes from the previously mentioned available database, and four relevant DEGs were identified with the highest repetition: IFNG (interferon gamma), ATP1B1 (sodium/potassium-transporting ATPase subunit beta-1), GAS6 (growth arrest specific 6), and PSEN1 (presenilin 1).

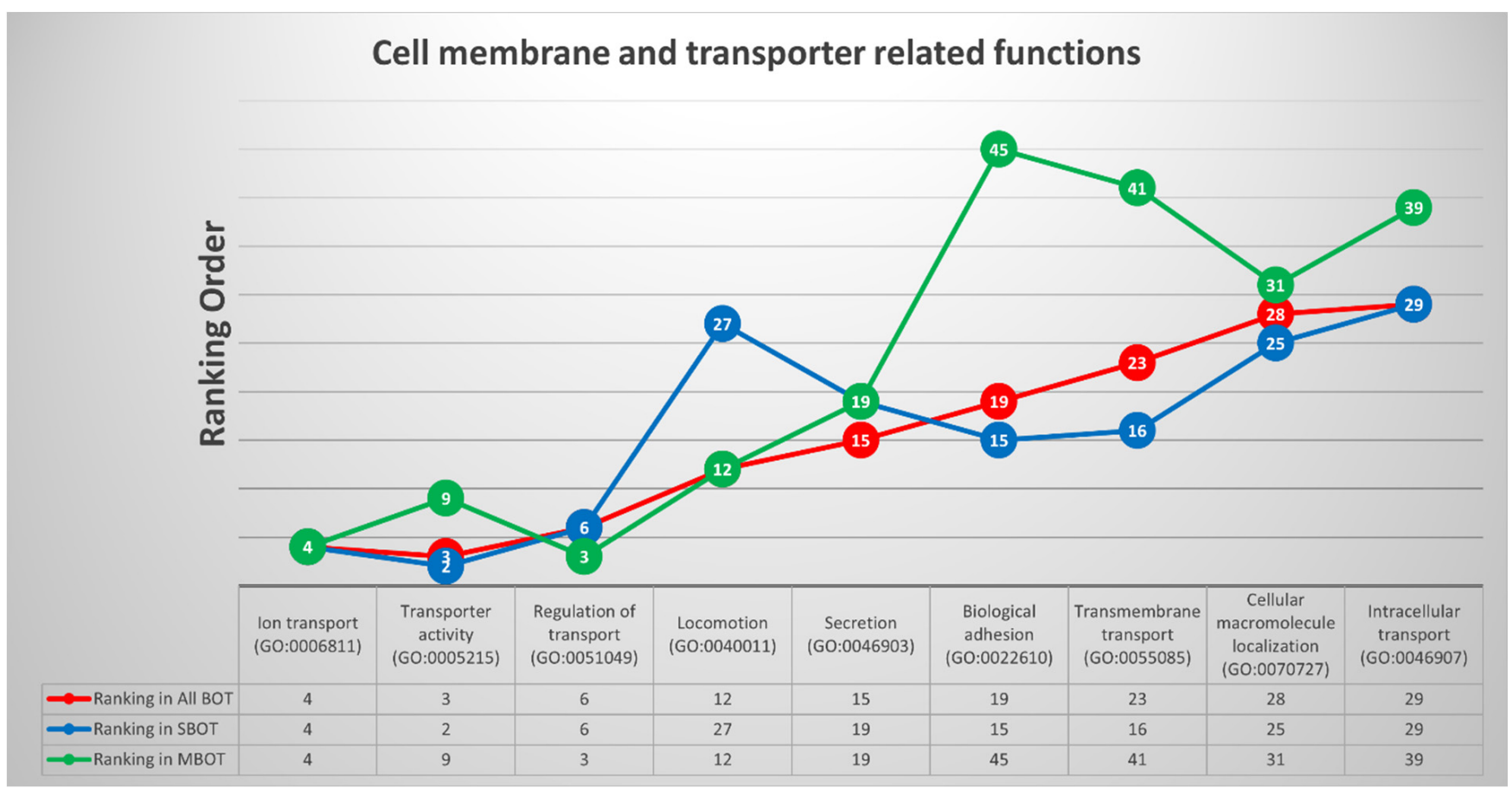

Cell Membrane and Transporter Related Functions

Most Relevant DEG: IFNG, ATP1B1, GAS6, and PSEN1

\begin{tabular}{cccccc}
\hline Order & GO ID & GO Term & Ranking in All BOTs & Ranking in SBOTs & Ranking in MBOTs \\
\hline $\mathbf{4}$ & GO:0006811 & Ion transport & 4 & 4 & 4 \\
\hline $\mathbf{5}$ & GO:0005215 & Transporter activity & 3 & 2 & 9 \\
\hline $\mathbf{6}$ & GO:0051049 & Regulation of transport & 6 & 27 & 12 \\
\hline $\mathbf{1 4}$ & GO:0040011 & Locomotion & 12 & 19 & 19 \\
\hline $\mathbf{1 6}$ & GO:0046903 & Secretion & 15 & 15 & 45 \\
\hline $\mathbf{2 5}$ & GO:0022610 & Biological adhesion & 19 & 16 & 41 \\
\hline $\mathbf{2 8}$ & GO:0055085 & Transmembrane transport & 23 & 25 & 31 \\
\hline $\mathbf{3 0}$ & GO:0070727 & Cellular macromolecule & 28 & 29 & 39 \\
\hline $\mathbf{3 3}$ & GO:0046907 & Intracellular transport & 29 & 29 & 2 \\
\hline
\end{tabular}

Figure 5. The trends and list with ranking orders of nine deregulated GO terms classified into cell membrane- and transporter response-related functions and the four most relevant DEGs with calculations and comparison. 


\subsection{Cell Cycle- and Signaling-Related Functions and Relevant DEGs}

We categorized 16 of the top 41 common deregulated GO terms into cell cycle- and signaling response-related functions according to their assigned functions, and the $16 \mathrm{GO}$ terms were "cell activation (GO:0001775)", "regulation of cell differentiation (GO:0045595)", "cytokine production (GO:0001816)", "homeostatic process (GO:0042592)", "positive regulation of multicellular organismal process (GO:0051240)", "cell-cell signaling (GO:0007267)", "negative regulation of response to stimulus (GO:0048585)", "chromosome organization (GO:0051276)", "apoptotic process (GO:0006915)", "cell cycle (GO:0007049)", "regulation of organelle organization (GO:0033043)", "positive regulation of signaling (GO:0023056)", "negative regulation of multicellular organismal process (GO:0051241)", "signaling receptor binding (GO:0005102)", "regulation of response to stress (GO:0080134)", and "response to endogenous stimulus (GO:0009719)." Using the same calculation method as above, we selected three relevant DEGs with the most statistically frequent occurrence among all genes annotating the 16 classified GO terms: CTNNB1 (catenin beta 1), GATA3, and IL1B (interleukin 1 beta). The results described in this section with ranking orders for each GO term among the three disease groups are presented fully in Figure 6.

\subsection{Cell Metabolism Related Functions and Relevant DEGs}

Based on the same principle, nine deregulated GO terms among three disease groups were classified into cell metabolism response-related functions: "small molecule metabolic process (GO:0044281)", “lipid metabolic process (GO:0006629)”, "regulation of protein modification process (GO:0031399)", "RNA metabolic process (GO:0016070)", "regulation of phosphorus metabolic process (GO:0051174)", "regulation of nucleobase-containing compound metabolic process (GO:0019219)", "DNA metabolic process (GO:0006259)", "protein phosphorylation (GO:0006468)", and "peptidyl-amino acid modification (GO:0018193)." Likewise, by utilizing statistics and calculations, ten relevant DEGs with the highest repetition in this group were selected and noted as follows: AKT1, SIRT1 (sirtuin 1), IL4 (interleukin 4), PDGFB (platelet-derived growth factor subunit B), MAPK3 (mitogen-activated protein kinase 3), SRC, TWIST1 (Twist-related protein 1), TGFB1 (transforming growth factor beta 1), ADIPOQ (adiponectin), and PPARGC1A (peroxisome proliferator-activated receptor gamma coactivator 1-alpha). All findings mentioned in this paragraph and the ranking orders with trends of the nine GO terms for each disease group are completely disclosed in Figure 7.

\subsection{The Most Significantly Dysfunctional Canonical Pathways and Representative DEGs}

We found 4833, 4065, and 5305 canonical pathways among all BOT, SBOT, and MBOT groups and arranged them in the order of relevance according to their $p$-values to discover the most dysfunctional pathway in each group. In Table 5, the top 20 most dysfunctional canonical pathways ranked by $p$-value are listed, and all $p$-values were statistically significant. "REACTOME galactose catabolism" ranked first in all BOT and SBOT groups, and "REACTOME glucuronidation" ranked first in the MBOT group. In addition, the top 20 pathways in the three disease groups had only one common dysfunctional pathway, "REACTOME galactose catabolism", which was also ranked fourth in the MBOT group. In addition, according to the gene set data downloaded from the GESA (Gene Set Enrichment Analysis) website (https:/ / www.gsea-msigdb.org/gsea/msigdb/cards/ REACTOME_GALACTOSE_CATABOLISM.html, accessed on 15 April 2021), we found five genes related to this dysfunctional pathway and their corresponding proteins (GALE, GALK1, GALT, PGM2, and PGM2 L1). Next, we used functional protein association networks (https:/ / string-db.org/, accessed on 15 April 2021) to compare these five proteins for the correlation of interactions with each other and found that GALT (galactose-1-phosphate uridylyltransferase) was the most promising gene and protein. 


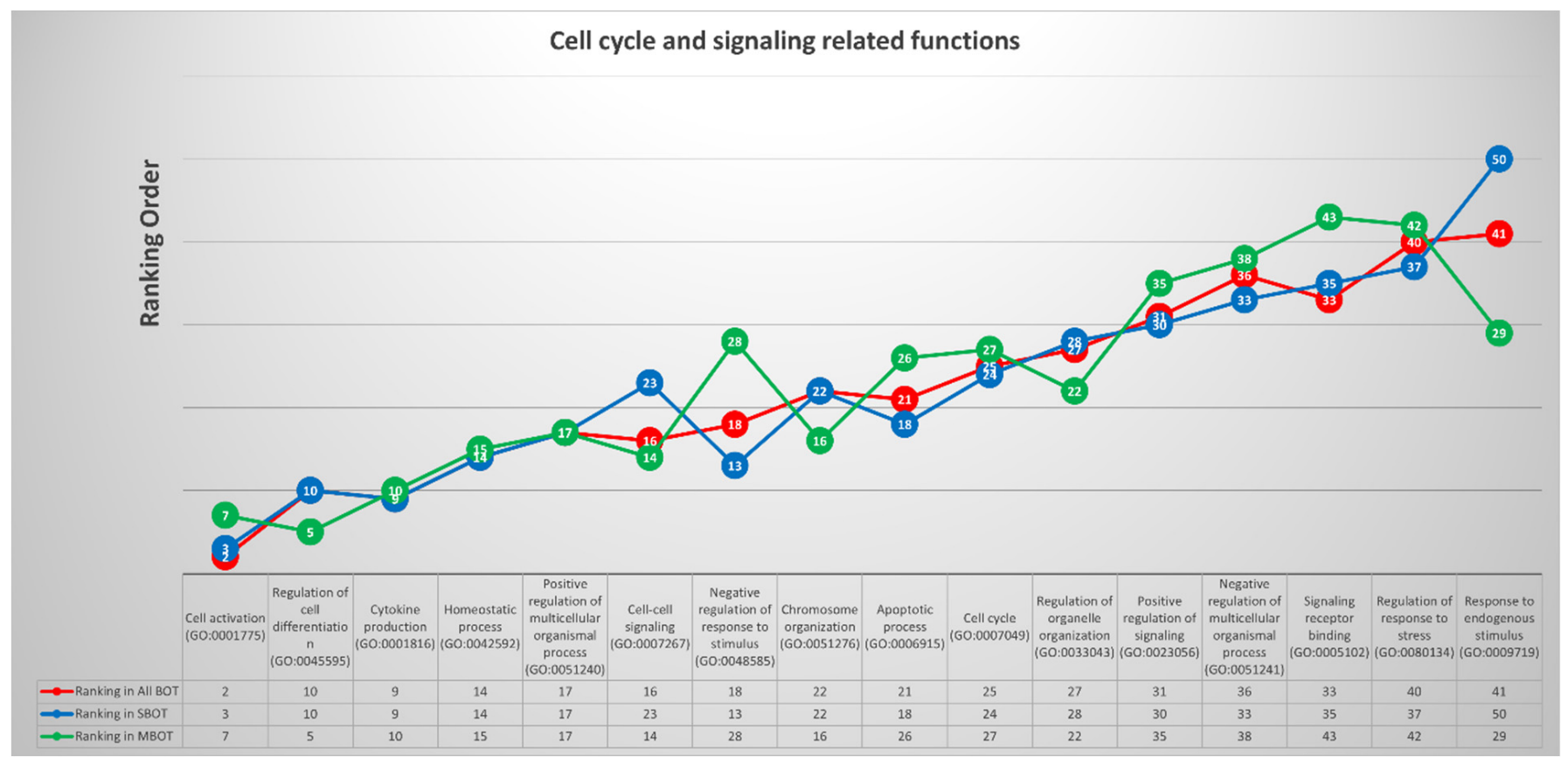

\begin{tabular}{|c|c|c|c|c|c|}
\hline \multicolumn{6}{|c|}{$\begin{array}{l}\text { Cell Cycle and Signaling-Related Functions } \\
\text { Most Relevant DEGs: CTNNB1, GATA3, and IL1B }\end{array}$} \\
\hline Order & GO ID & GO Term & $\begin{array}{l}\text { Ranking in All } \\
\text { BOTs }\end{array}$ & $\begin{array}{l}\text { Ranking in } \\
\text { SBOTs }\end{array}$ & $\begin{array}{l}\text { Ranking in } \\
\text { MBOTs }\end{array}$ \\
\hline 3 & GO:0001775 & Cell activation & 2 & 3 & 7 \\
\hline 7 & GO:0045595 & Regulation of cell differentiation & 10 & 10 & 5 \\
\hline 8 & GO:0001816 & Cytokine production & 9 & 9 & 10 \\
\hline 12 & GO:0042592 & Homeostatic process & 14 & 14 & 15 \\
\hline 15 & GO:0051240 & $\begin{array}{l}\text { Positive regulation of multicellular } \\
\text { organismal process }\end{array}$ & 17 & 17 & 17 \\
\hline 17 & GO:0007267 & Cell-cell signaling & 16 & 23 & 14 \\
\hline 19 & GO:0048585 & $\begin{array}{l}\text { Negative regulation of response to } \\
\text { stimulus }\end{array}$ & 18 & 13 & 28 \\
\hline 20 & GO:0051276 & Chromosome organization & 22 & 22 & 16 \\
\hline 22 & GO:0006915 & Apoptotic process & 21 & 18 & 26 \\
\hline 23 & GO:0007049 & Cell cycle & 25 & 24 & 27 \\
\hline 24 & GO:0033043 & $\begin{array}{l}\text { Regulation of organelle } \\
\text { organization }\end{array}$ & 27 & 28 & 22 \\
\hline 32 & GO:0023056 & Positive regulation of signaling & 31 & 30 & 35 \\
\hline 34 & GO:0051241 & $\begin{array}{l}\text { Negative regulation of multicellular } \\
\text { organismal process }\end{array}$ & 36 & 33 & 38 \\
\hline 35 & GO:0005102 & Signaling receptor binding & 33 & 35 & 43 \\
\hline 38 & GO:0080134 & Regulation of response to stress & 40 & 37 & 42 \\
\hline 39 & GO:0009719 & Response to endogenous stimulus & 41 & 50 & 29 \\
\hline
\end{tabular}

Figure 6. The trends and list with ranking orders of 16 deregulated GO terms classified into cell cycle- and signaling response-related functions and the three most relevant DEGs with calculations and comparison. 


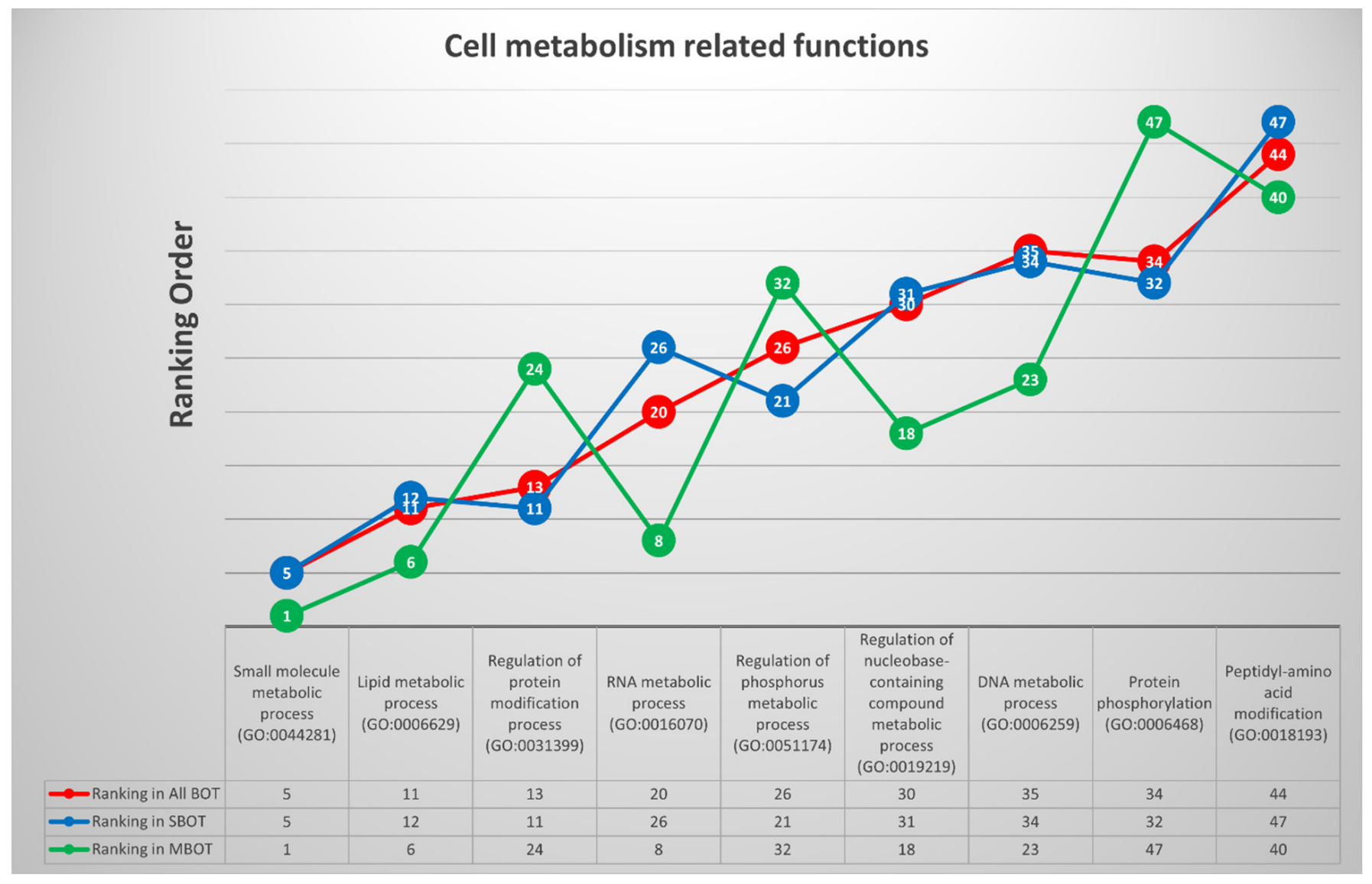

Cell Metabolism Related Functions

Most Relevant DEGs: AKT1, SIRT1, IL4, PDGFB, MAPK3, SRC, TWIST1, TGFB1, ADIPOQ, and PPARGC1A

\begin{tabular}{|c|c|c|c|c|c|}
\hline Order & GO ID & GO Term & $\begin{array}{c}\text { Ranking in All } \\
\text { BOTs }\end{array}$ & $\begin{array}{l}\text { Ranking in } \\
\text { SBOTs }\end{array}$ & $\begin{array}{l}\text { Ranking in } \\
\text { MBOTs }\end{array}$ \\
\hline 2 & GO:0044281 & Small molecule metabolic process & 5 & 5 & 1 \\
\hline 10 & GO:0006629 & Lipid metabolic process & 11 & 12 & 6 \\
\hline 13 & GO:0031399 & $\begin{array}{l}\text { Regulation of protein modification } \\
\text { process }\end{array}$ & 13 & 11 & 24 \\
\hline 18 & GO:0016070 & RNA metabolic process & 20 & 26 & 8 \\
\hline 26 & GO:0051174 & $\begin{array}{l}\text { Regulation of phosphorus } \\
\text { metabolic process }\end{array}$ & 26 & 21 & 32 \\
\hline 27 & GO:0019219 & $\begin{array}{c}\text { Regulation of } \\
\text { nucleobase-containing compound } \\
\text { metabolic process }\end{array}$ & 30 & 31 & 18 \\
\hline 31 & GO:0006259 & DNA metabolic process & 35 & 34 & 23 \\
\hline 36 & GO:0006468 & Protein phosphorylation & 34 & 32 & 47 \\
\hline 41 & GO:0018193 & Peptidyl-amino acid modification & 44 & 47 & 40 \\
\hline
\end{tabular}

Figure 7. The trends and list with ranking orders of nine deregulated GO terms classified into cell metabolism responserelated functions and the ten most relevant DEGs with calculations and comparison. 
Table 5. The top 20 most dysfunctional canonical pathways among all BOT, SBOT, and MBOT groups ranked by $p$-values.

\begin{tabular}{|c|c|c|c|c|c|c|}
\hline \multirow{2}{*}{$\begin{array}{l}\text { Category } \\
\text { Ranking }\end{array}$} & \multicolumn{2}{|l|}{ All BOTs } & \multicolumn{2}{|l|}{ Serous BOT } & \multicolumn{2}{|l|}{ Mucinous BOT } \\
\hline & Geneset Name & $p$-Values & Geneset Name & $p$-Values & Geneset Name & $p$-Values \\
\hline 1 & REACTOME galactose catabolism & $1.9273 \times 10^{-34}$ & REACTOME galactose catabolism & $8.1608 \times 10^{-32}$ & REACTOME glucuronidation & $6.7592 \times 10^{-10}$ \\
\hline 3 & $\begin{array}{l}\text { RODRIGUES thyroid carcinoma } \\
\text { upregulation }\end{array}$ & $3.6094 \times 10^{-33}$ & $\begin{array}{l}\text { BIOCARTA Antigen dependent B } \\
\text { Cell activation pathway }\end{array}$ & $5.6450 \times 10^{-29}$ & $\begin{array}{l}\text { CASTELLANO HRAS and NRAS } \\
\text { targets downregulation }\end{array}$ & $2.8989 \times 10^{-9}$ \\
\hline 5 & BIOCARTA stem pathway & $6.7888 \times 10^{-33}$ & $\begin{array}{c}\text { KANG cisplatin resistance } \\
\text { upregulation }\end{array}$ & $5.6450 \times 10^{-29}$ & $\begin{array}{c}\text { NADELLA PRKAR1A targets } \\
\text { downregulation }\end{array}$ & $5.3670 \times 10^{-9}$ \\
\hline 6 & $\begin{array}{c}\text { KANG cisplatin resistance } \\
\text { upregulation }\end{array}$ & $6.7888 \times 10^{-33}$ & $\begin{array}{l}\text { REACTOME HATs acetylate } \\
\text { histones }\end{array}$ & $5.6450 \times 10^{-29}$ & $\begin{array}{l}\text { REACTOME molybdenum } \\
\text { cofactor biosynthesis }\end{array}$ & $5.3670 \times 10^{-9}$ \\
\hline 7 & $\begin{array}{l}\text { TERAO AOX4 targets skin } \\
\text { downregulation }\end{array}$ & $6.7888 \times 10^{-33}$ & REACTOME interleukin 2 signaling & $5.6450 \times 10^{-29}$ & $\begin{array}{l}\text { REACTOME RUNX3 regulates } \\
\text { BCL2 L11 (BIM) transcription }\end{array}$ & $5.3670 \times 10^{-9}$ \\
\hline 9 & $\begin{array}{l}\text { REACTOME HATs acetylate } \\
\text { histones }\end{array}$ & $9.6321 \times 10^{-33}$ & $\begin{array}{l}\text { STAMBOLSKY targets of mutated } \\
\text { TP53 upregulation }\end{array}$ & $5.6450 \times 10^{-29}$ & $\begin{array}{l}\text { GARGALOVIC response to } \\
\text { oxidized phospholipids green } \\
\text { module downregulation }\end{array}$ & $1.5393 \times 10^{-8}$ \\
\hline 10 & REACTOME interleukin 2 signaling & $9.6321 \times 10^{-33}$ & $\begin{array}{l}\text { TERAO AOX4 targets skin } \\
\text { downregulation }\end{array}$ & $5.6450 \times 10^{-29}$ & $\begin{array}{l}\text { GAUSSMANN MLL-AF4 fusion } \\
\text { proteins targets set B } \\
\text { downregulation }\end{array}$ & $1.5393 \times 10^{-8}$ \\
\hline 11 & $\begin{array}{c}\text { STAMBOLSKY targets of mutated } \\
\text { TP53 upregulation }\end{array}$ & $9.9179 \times 10^{-33}$ & $\begin{array}{c}\text { WANG response to androgen } \\
\text { upregulation }\end{array}$ & $7.5300 \times 10^{-29}$ & $\begin{array}{c}\text { KANG cisplatin resistance } \\
\text { downregulation }\end{array}$ & $1.5393 \times 10^{-8}$ \\
\hline
\end{tabular}


Table 5. Cont.

\begin{tabular}{|c|c|c|c|c|c|c|}
\hline \multirow{2}{*}{$\begin{array}{l}\text { Category } \\
\text { Ranking }\end{array}$} & \multicolumn{2}{|l|}{ All BOTs } & \multicolumn{2}{|l|}{ Serous BOT } & \multicolumn{2}{|l|}{ Mucinous BOT } \\
\hline & Geneset Name & $p$-Values & Geneset Name & $p$-Values & Geneset Name & $p$-Values \\
\hline 12 & $\begin{array}{l}\text { REACTOME RUNX1 and FOXP3 } \\
\text { control the development of } \\
\text { regulatory T lymphocytes }\end{array}$ & $1.7040 \times 10^{-32}$ & $\begin{array}{l}\text { HASEGAWA tumorigenesis by RET } \\
\text { allele with the MEN2A mutation } \\
\text { (C634R) }\end{array}$ & $8.1498 \times 10^{-29}$ & $\begin{array}{l}\text { REACTOME formyl peptide } \\
\text { receptors bind formyl peptides } \\
\text { and many other ligands }\end{array}$ & $1.5393 \times 10^{-8}$ \\
\hline 13 & JU aging TERC targets upregulation & $4.1179 \times 10^{-32}$ & $\begin{array}{l}\text { SCHWAB targets of BMYB } \\
\text { polymorphic variants } \\
\text { downregulation }\end{array}$ & $8.1498 \times 10^{-29}$ & REACTOME mRNA editing & $1.5393 \times 10^{-8}$ \\
\hline 14 & $\begin{array}{l}\text { BIOCARTA Antigen dependent B } \\
\text { Cell activation pathway }\end{array}$ & $5.6577 \times 10^{-32}$ & $\begin{array}{l}\text { KREPPEL CD99 targets } \\
\text { downregulation }\end{array}$ & $1.1090 \times 10^{-28}$ & $\begin{array}{c}\text { ABRAHAM amyloidosis plasma } \\
\text { cells (ALPC) compared to } \\
\text { multiple myeloma (MM) cells } \\
\text { upregulation }\end{array}$ & $1.6662 \times 10^{-8}$ \\
\hline 15 & BIOCARTA 4-1BB (CD137) pathway & $1.0825 \times 10^{-31}$ & $\begin{array}{l}\text { NAGY STAGA complex } \\
\text { components in human }\end{array}$ & $1.5310 \times 10^{-28}$ & $\begin{array}{l}\text { ACEVEDO liver cancer with } \\
\text { H3K27 me3 upregulation }\end{array}$ & $1.6662 \times 10^{-8}$ \\
\hline 16 & $\begin{array}{c}\text { LOPEZ mesothelioma survival } \\
\text { downregulation }\end{array}$ & $2.4323 \times 10^{-31}$ & $\begin{array}{l}\text { WANG response to forskolin } \\
\text { upregulation }\end{array}$ & $2.1622 \times 10^{-28}$ & $\begin{array}{l}\text { AMIT EGF response } 20 \text { min after } \\
\text { stimulation of MCF10A cells }\end{array}$ & $1.6662 \times 10^{-8}$ \\
\hline 18 & $\begin{array}{l}\text { PID JNK signaling in the CD4+ TCR } \\
\text { pathway }\end{array}$ & $5.6082 \times 10^{-31}$ & $\begin{array}{l}\text { REACTOME reversible hydration of } \\
\text { carbon dioxide }\end{array}$ & $5.8648 \times 10^{-28}$ & $\begin{array}{l}\text { AMIT serum response } 480 \text { min } \\
\text { after stimulation of MCF10A cells }\end{array}$ & $1.6662 \times 10^{-8}$ \\
\hline 19 & $\begin{array}{l}\text { NAGY STAGA complex } \\
\text { components in human }\end{array}$ & $7.9222 \times 10^{-31}$ & BIOCARTA 4-1BB (CD137) pathway & $7.8095 \times 10^{-28}$ & $\begin{array}{c}\text { AMUNDSON response to sodium } \\
\text { arsenite }\end{array}$ & $1.6662 \times 10^{-8}$ \\
\hline 20 & $\begin{array}{l}\text { IKEDA miR-30 microRNA targets } \\
\text { downregulation }\end{array}$ & $1.0328 \times 10^{-30}$ & BIOCARTA Complement pathway & $8.5975 \times 10^{-28}$ & AUNG gastric cancer & $1.6662 \times 10^{-8}$ \\
\hline
\end{tabular}


2.11. Verification with Immunohistochemical Analysis of Anti-IL6 and Anti-GALT Expression between BOTs and Normal Ovarian Tissues

To verify the abovementioned related pathogenic mechanisms and to explore clinical manifestations specifically of the identified DEGs involved in the tumorigenesis process of BOTs, we collected related clinical samples from a cohort (BOTs, $n=9$; normal control group, $n=9$ ) and then performed immunostaining with anti-IL6 and anti-GALT antibodies separately. Among all deregulated GO terms and classified categories, the general ranking and order occupied by the immune and inflammatory response-related functions was the highest overall; as a result, we picked up the IL6 gene selected from the immune and inflammatory response-related functions for the representative gene among 19 DEGs due to its close relationship with ovarian tumors [53-56]. Together with the anti-GALT antibody, we used immunohistochemical analysis of the anti-IL6 antibody between the BOT and control groups to assess the clinically meaningful significance of IL6 and GALT. During the entire process, the pathologists interpreted and verified to obtain the following results on average repeatedly. The results revealed higher expression levels of IL6 and GALT in BOT samples than in normal samples (Figure 8A). Pathologists and quantification of the immunostaining scores of IL6 and GALT levels were performed using SPSS software (IBM Corp., Released 2013, IBM SPSS Statistics for Windows, Version 22.0, Armonk, NY, USA: IBM Corp.). A higher mean value with statistical significance of IL6 and GALT expression in samples of BOTs was clearly shown compared with the control group (Figure 8B). These results supported the above deductions, indicating that many deregulated functions inferred from integrative GO enrichment analysis, including immune and inflammatory response-related, cell membrane-related and transporter-related, cell cycle- and signalingrelated, and cell metabolism-related functions, indeed contributed to the pathogenesis of BOTs. Likewise, these results also proved that the dysfunctional pathway of galactose catabolism played a role in the tumorigenesis of BOTs. All results provide preliminary clinical evidence to support the previously proposed pathogenic tumorigenesis of BOTs. 

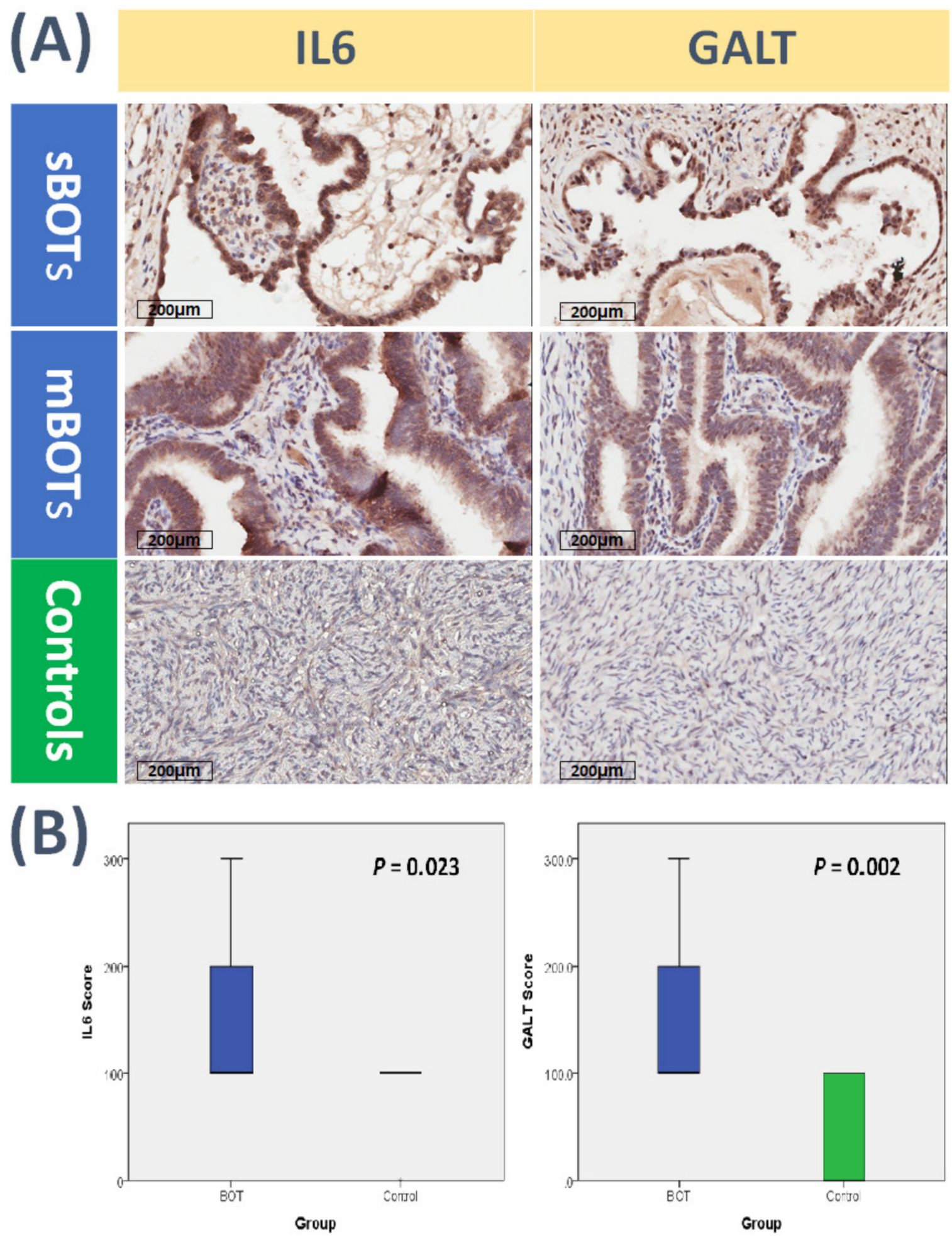

Figure 8. Immunohistochemical analysis of clinical samples between patients with BOTs and the control group. (A) Clinical samples from patients with BOTs $(n=9)$ and from the normal group $(n=9)$ were immunostained with anti-IL6 antibody (brown color, left straight row) and anti-GALT antibody (brown color, right straight row), and the parts shown in the horizontal row are the immunostaining results of serous BOTs, mucinous BOTs, and control groups from top to bottom. (B) Box plots for expressed IL6 and GALT between BOT patients and the control group. The expression levels of IL6 and GALT in all clinical samples are presented with quantification, and the statistically meaningful mean values of IL6 and GALT expression in the BOT group were higher than those in the normal group. 


\section{Discussion}

In this study, we utilized an integrated polygenic analytical model with the concept of GO (gene ontology) and GSR (gene set regularity) indices computed based on gene expression ranking to further explore the complex and diverse biomolecular and genetic functions of BOTs and their two most common subtypes (SBOT and MBOT) and obtained statistically meaningful results. Although both subtypes belong to BOTs, serous and mucinous are different in clinical features, histopathology, and pathogenesis, although there are many commonalities found in this research. For example, in serous BOTs, clinically, there are sometimes multiple intra-abdominal metastasis-like lesions similar to ovarian cancer. In contrast to the serous subtype, mucinous BOTs usually form a single large tumor shape. In recent years, in tumorigenesis research, the epithelial-to-mesenchymal transition (EMT) has been a key concept in research on ovarian neoplasms and is a reversible process in cell differentiation, morphogenesis, growth, and change of function in which epithelial cells obtain mesenchymal cell characteristics by losing polarity and adhesion of cells and increasing cellular migratory motility $[57,58]$. Although BOTs are not entirely recognized as malignant tumors and are not seen as a necessary process of transformation into ovarian cancer, in this study, we found some biomarkers related to EMTs, such as IL6, AKT1, MAPK3, SRC, TWIST1, and TGFB1 [59-61]. These additional findings may be worthy of further investigation in the future [62]. Next, we discuss and explain the major categories mentioned in this research.

Regarding immunity- and inflammation-related functions, whether modulating or regulating the immune system process (GO:0002682), progressing to the development of the immune system against internal and invasive threats (GO:0002520) or any process of the immune system potentially contributing to immune responses (GO:0002252), the rankings of GO terms among the three disease groups were very high, and we also found that the most significant DEGs selected by repeated comparisons were IL6 and CCR2. In addition, the cell cycle, an important biological periodic function, is involved in the process of tumorigenesis, and it is worth studying further. In addition, message transmission, whether biogenetic signal transduction occurs inside the cell, across the cell membranes, or between cells, also takes a specific place in the pathogenesis of BOTs. In this study, we sorted out that transportive movement of ions (GO:0006811), active ability of transporters (GO:0005215), modulation of movement of substances (GO:0051049), self-propelled movement of a cell or organism (GO:0040011), controlled biological emancipation (GO:0046903), attachment of a cell or organism to another cell or other organism (GO:0022610), transport of a solute across a lipid bilayer (GO:0055085), macromolecule transported forward to any specific location of a cell (GO:0070727), and the directed movement of substances within a cell (GO:0046907) as cell membrane- and transporterrelated functions and assembled four associated relevant DEGs (IFNG, ATP1B1, GAS6, PSEN1). In addition, we also sorted out 16 clearly defined GO terms ("Cell activation (GO:0001775)”, "Regulation of cell differentiation (GO:0045595)”, "Cytokine production (GO:0001816)", “Homeostatic process (GO:0042592)”, "Positive regulation of multicellular organismal process (GO:0051240)", “Cell-cell signaling (GO:0007267)”, “Negative regulation of response to stimulus (GO:0048585)", “Chromosome organization (GO:0051276)", "Apoptotic process (GO:0006915)", "Cell cycle (GO:0007049)", "Regulation of organelle organization (GO:0033043)", "Positive regulation of signaling (GO:0023056)", "Negative regulation of multicellular organismal process (GO:0051241)", "Signaling receptor binding (GO:0005102)", "Regulation of response to stress (GO:0080134)", and "Response to endogenous stimulus (GO:0009719)") as mentioned earlier that were classified as cell cycle- and signaling-related functions and used statistical methods to find three highly related DEGs (CTNNB1, GATA3, and IL1B). We also confirmed the role of cell metabolism in the pathogenetic process of BOTs. Deregulated genetic expression and dysfunctional reprogramming pathways of cell metabolism accompanied by both direct and indirect consequences of tumorigenic mutations cause tumorigenesis. Gene expression, cellular differentiation, and the tumor microenvironment are all influenced by associated metabolic reprogramming 
and intracellular and extracellular metabolites to acquire necessary nutrients [63]. In this study, we sorted out that cellular metabolic processes involving deoxyribonucleic acid (GO:0006259), ribonucleic acid (GO:0016070), regulation of nucleobase-containing compounds (GO:0019219), lipids (GO:0006629), and small molecules (GO:0044281), as well as alteration and modification of peptidyl-amino acid (GO:0018193), protein phosphorylation (GO:0006468), regulation of protein modification (GO:0031399), and phosphorus metabolic process (GO:0051174) are very meaningful and the selected ten DEGs do have roles in cell metabolism and tumorigenesis of BOTs.

This article also analyzed and investigated related DEGs, and the following is a brief description of each DEG. In addition to utilizing an immunohistochemical method to verify that IL6, a potential regulatory biomarker, in BOTs does have a significantly higher performance than controls, IL6 has certain accessorial functions associated with nearby immune-related cells in the microenvironment for the enhancement of benign or malignant ovarian tumors [53-56,64,65]. CCR2 can bind with chemokine ligand 2 (CCL2) on macrophages and monocytes to promote the expression and differentiation of $\mathrm{T}$ cells and to regulate related inflammatory cytokines by activating the PI3K cascade and small $\mathrm{G}$ protein GTPases. CCR2 plays a certain role in the tumorigenesis of ovarian tumors through immune cells and related regulatory responses in the microenvironment, which is also worthwhile to explore in the future [17,56,66-69]. IFNG (IFN $\gamma$ ), the only type II interferon, is an important signal activator of macrophages and inducer of innate and adaptive immunity in accordance with other immune-related cells or cytokines to exert antiproliferative and antitumor effects $[66,70,71]$. ATP1B1 is mainly responsible for establishing and maintaining the electrochemical gradients of $\mathrm{Na}$ and $\mathrm{K}$ ions across the plasma membrane, and the expression of ATP1B1 may have a suppressive effect that needs further validation [72,73]. GAS6 is usually thought to be related to cell proliferation, chemotaxis and survival, and stronger expression in BOTs implies associated epithelial-mesenchymal transition in the tumor microenvironment [74,75]. PSEN1 (Presenilin-1, PS-1) is considered to regulate amyloid precursor protein (APP) catalysis and is thought to be involved in Notch and Wnt signaling cascades; however, the role of PSEN1 in BOTs is rarely known and needs to be further validated $[76,77]$. CTNNB1 ( $\beta$-catenin) is a crucial component of the Wnt signaling pathway for the coordination and regulation of gene transcription and cellcell adhesion through phosphorylation and mutation of the CTNNB1 gene, and alteration of the $\beta$-catenin pathway is thought to participate in the pathogenic process of BOTs [78-81]. GATA3 is considered a transcriptional activator for the regulation of T-cell development and several inflammatory and allergic responses and was suggested as a regulator in benign ovarian Brenner tumors and serous tumors with prognostic value $[4,82,83]$. IL1B (interleukin 1 beta, IL-1 $\beta$ ) is a potent proinflammatory mediator of the inflammatory response, as well as having a relationship in cell proliferation, differentiation, and apoptosis, whereas IL1B can promote tumorigenesis through the inflammatory response, which still needs further verification among BOTs [84-86]. AKT1, also known as Akt/PKB, participates in the PTEN/PI3K/Akt signaling pathway to mediate apoptosis, metabolism, cell proliferation, and growth and is frequently dysregulated during tumorigenesis [81,87]. SIRT1 (Sirtuin1), a class III histone deacetyltransferase and a nicotinamide adenine dinucleotide-dependent deacetylase, exerts protective effects against oxidative stress, genomic instability, and DNA damage, and SIRT1 overexpression may play a crucial role in the tumorigenesis of BOTs and the carcinogenesis of early-stage ovarian cancer [88-90]. IL4 (interleukin 4), as a key regulator in humoral and adaptive immunity, could induce Th2 cell differentiation and may have a significant effect on the pathogenesis of BOTs [56,91]. PDGFB (platelet-derived growth factor $\mathrm{B}$ ) regulates cell growth and division and plays an important role in neoangiogenesis, particularly in tumorigenesis among both BOTs and EOCs [92-95]. MAPK3 (mitogenactivated protein kinase 3), also known as ERK1 (extracellular signal-regulated kinases 1), acts in the mitogenic Ras/Raf/MEK/ERK signaling cascades to regulate cell proliferation, differentiation, and cell cycle progression, and MAPK3 is a key factor for the pathogenesis of BOTs accompanied by a high prevalence of $K R A S$ and $B R A F$ mutations $[33,81,96,97]$. 
SRC, a nonreceptor protein tyrosine kinase, participates in the regulation of cell growth and embryonic development and promotes survival, angiogenesis, proliferation and invasion pathways while being activated or overexpressed during tumor development $[43,98,99]$. TWIST1, acting as an epithelial-mesenchymal transition transcriptional regulator, plays an important role in escaping apoptosis and metastasis, with increased expression stepwise from benign, borderline, to malignant ovarian tumors [100-102]. TGFB1 could conduct several cellular functions, such as cell proliferation, differentiation, growth, and apoptosis, and TGFB1 could also work with other immune-related cells in the microenvironment to show proangiogenic and prometastatic features in addition to the dual role of being an enemy and friend in tumorigenesis [56,103,104]. ADIPOQ (adiponectin), mainly produced and associated with adipose tissue, modulates numerous metabolic processes consisting of regulation of glucose level, metabolism of fatty acids, and insulin sensitivity and may take some part in cell growth, angiogenesis, and tissue remodeling during tumorigenesis with significantly lower levels in cancerous ovarian samples [105-108]. PPARGC1A (PGC-1 $\alpha$ ) participates essentially in metabolic reprogramming involved in gluconeogenesis, fatty acid metabolism, and mitochondrial biogenesis and facilitates a flexible metabolic profile to benefit tumor cells overexpressing PPARGC1A in human epithelial ovarian cancer cells [109-112]. Furthermore, we found the most common and meaningful dysfunctional canonical pathways among the three disease groups, galactose metabolism (REACTOME GALACTOSE CATABOLISM), and discovered a representative DEG, GALT. In the human liver, galactose is converted into glucose-6-phosphate through the biophysiological reaction galactose metabolism for rapid conversion from galactose to glucose, and GALT participates in a prominent position for catalyzing the second step of the Leloir pathway of galactose metabolism [113]. Galactosaemia caused by mutation of GALT or GALT deficiency could induce ovarian toxicity, and polymorphism of GALT with galactose consumption and metabolism may be associated with the development of BOTs and the risk of EOCs [114-119]. However, the roles of all DEGs and concomitant influences mentioned above in the tumorigenesis of BOTs require additional research data to explore further and to confirm definitively.

The limitations of this study are as follows. The first limitation is the distribution of case groups. The numbers of SBOTs and MBOTs are very different, and SBOTs are more common because most of the populations sampled by the database in this experiment are patients from Western countries and most of the patients with BOTs from Western countries are SBOTs; therefore, the presentative consequence would cause the results of the SBOT group to be similar to those of the All-BOTs group but very different from those of the MBOT group. Perhaps in the future, a more complete gene expression profile database could be established to reduce individual differences between ethnic groups in a prospective or retrospective cohort study on a larger scale globally or in parts of Eastern Asian countries. Second, some limitations of the integrative analysis model used in this research are observed including that not all human functions were concluded or defined from the gene set databases of the GO terms and the canonical pathway. The probable detectability of the GSR model was noted owing to unchanged GSR indices and missed errors during the process of converting levels to the ordering of gene expression if the expression levels were undetectable, false positivity was made from the indistinguishable elements of disparate gene sets, and the heterogenicity of different cellular histopathological compositions in tumor and control samples was utilized. Although coupled with the statistically significant high sensitivity, specificity, and accuracy of this experiment, these deficiencies may not be apparent in the performance of the overall results. As a result, more accurate programming syntax design and more specific screening of samples could be requested to avoid these problems in the future. Finally, our study mainly explored the common pathogenic mechanisms among BOTs; however, it was slightly hindered by the extracted data collected from the GO database due to insufficient research at present and the gathered clinical specimens with fewer numbers and limited funds. However, the results were statistically significant and distinctly clear in terms of clinical verification 
by immunostaining. More extensive BOT specimens, more worldwide academic research databases of various subtypes, and more detailed in-depth comparisons of the differences in pathogenic mechanisms of different subtypes with large-scale funding and experimental tests may be required to continue in the future.

\section{Materials and Methods}

\subsection{Computing the GSR Indices and Reconstructing the Functionome}

The GSR index was computed and extracted from the gene expression datasets by modifying the differential rank conservation (DIRAC) algorithm [120], which measures the changes of the ordering among the gene elements in a gene set between the gene expression datasets of all BOTs, SBOTs, MBOTs, and the most common gene expression ordering in the normal control samples. The details of the GSR model and the computing procedures are described in our previous studies [45-50]. Microarray gene expression datasets for BOTs and normal ovarian samples were downloaded from the GEO database. The corresponding gene expression levels were extracted and built according to the gene elements in the GO gene set and converted to ordinal data based on their expression levels. The GSR index is the ratio of gene expression ordering in a gene set between the case and the most common gene expression ordering among the normal ovarian tissue samples that ranges from 0 to 1 , where 0 indicates the most dysregulated state of a function, i.e., oppositely ordered gene set regularities between BOT cases and the normal state; while 1 indicates that the regularity in a gene set remains the same between the case and the most common gene expression orderings in the normal controls. The measurement of GSR indices was carried out in the $\mathrm{R}$ programming language. A functionome is defined as the complete set of biological functions, and the definition for comprehensive biological functions is not yet available at present; as such, we annotated and pronounced the human functionome by using the $10,271 \mathrm{GO}$ gene set defined functions. As a result, the functionome utilized in this study is defined as the assembly of 10,271 GSR indices for each sample.

\subsection{Microarray Dataset Collection}

The selection criteria for the microarray gene expression datasets from the GEO database were as follows: (1) the BOT disease samples and normal control samples should originate from ovarian tissue; (2) the datasets should provide sufficient information about the diagnosis and clinical histopathological subtypes of BOTs; and (3) any gene expression profile in a dataset was abandoned if it contained missing data.

\subsection{Statistical Analysis}

The Mann-Whitney U-test was used to test the differences among all BOTs, the major two BOT subtype groups and the controls and then corrected by multiple hypotheses using the false discovery rate (Benjamini-Hochberg procedure). The $p$-value was set at $p<0.05$.

\subsection{Classification and Prediction by Machine Learning}

The function "kvsm" provided by the "kernlab" (version 0.9-27; Comprehensive R Archive Network; https:/ / cran.r-project.org/, accessed on 15 April 2021), an R package for kernel-based machine-learning methods, was used to classify and predict the patterns of the GSR indices. The accuracies of the classification and predictions by SVM were measured by k-fold cross-validation. The results of ten repeated predictions were used to assess the performance of binary classification. AUC was computed using the R package "pROC" [121]. The performance of multiclass classification was assessed using the ten repeated prediction accuracies for each of the BOT and the two BOT subtype groups (all BOTs, SBOTs, and MBOTs).

\subsection{Set Analysis}

All possible logical relationship among the dysregulated gene sets of the categorized BOT subtype groups (all BOTs, SBOTs, and MBOTs) are displayed using the R package 
programming (version 1.6.16; Comprehensive R Archive Network; https: / cran.r-project. org/, accessed on 15 April 2021).

\subsection{Clinical Samples and Immunohistochemistry (IHC) Analysis}

The clinical samples for the present study contained nine gathered BOT cases (BOTs, $n=9$, including three serous BOTs, five mucinous BOTs and one seromucinous BOT) and nine controlled cases (normal, $n=9$ ). All tissues from the cases of BOTs were collected from women who underwent surgical treatment as their therapeutic guideline. The source of all clinical normal tissues was taken from the patients after menopause or in perimenopausal status and agreed to remove the uterus and remove bilateral ovaries and fallopian tubes because of myoma or female genital organ prolapse after explaining and signing the informed consent. The patients were diagnosed and treated, and their tissues were placed in a bank at the Tri-Service General Hospital, Taipei, Taiwan. The Institutional Review Board of the Tri-Service General Hospital, National Defense Medical Center approved the study (2-107-05-043, approved on 26 October 2018; 2-108-05-091, approved on 20 May 2019). Informed consent was acquired from all patients and control subjects. All clinical tissue samples were confirmed under quantitative histopathology diagnosed by pathologists, and the assessment of the results of the immunohistochemical staining with quantitative scoring methods was scored by multiplying the intensity (I) by the percentage of positive cells $(\mathrm{P})$ for all biomarkers used in this study (formula is shown as IHC score $(\mathrm{Q})=\mathrm{I} \times \mathrm{P}$; maximum $=300)[122,123]$. The detailed results of all scores for GALT and IL among clinical samples are listed in Table S3.

\section{Conclusions}

Borderline ovarian tumor (BOT) is a peculiar subtype of epithelial tumors of the ovary with intermediate features between benign ovarian neoplasms and invasive ovarian carcinomas. In this study, we properly made use of integrative gene ontology-based analysis to investigate the most likely biomolecular and pathogenetic mechanisms among tumorigenesis of BOTs arising from normal ovarian tissues. With the assistance of machine learning, we applied a genome-wide expression profile to evaluate the various global functionomes and related pathogenic pathways of all BOTs, SBOTs, and MBOTs compared with controls and first found that there were obvious deviations in terms of the GSR index between all case samples and the control group, especially the MBOT subtype. Interestingly, we next utilized this integrated method systematically to draw 41 significantly common GO terms from the consolidated functionome that could be classified into four crucial categories consisting of three immune and inflammatory response-related functions, nine cell membraneand transporter-related functions, 16 cell cycle- and signaling-related functions, nine cell metabolism-related functions, and four GO terms not belonging to the first four categories. Then, 19 genes corresponding to the above biological functions with high possibility were cross-checked and sorted. Moreover, we also discovered that the dysfunctional galactose catabolism pathway played a role during the formation of all BOTs, SBOTs, and MBOTs with the top few rankings. Finally, verification by using immunohistochemistry demonstrated elevated expression of IL6 and GALT in BOTs compared with normal ovarian tissue, which supported that dysregulated immunological function and dysfunctional metabolic pathways definitely participated in the tumorigenesis of BOTs. All results of this study are statistically significant, mainly because of the high sensitivity, specificity, and accuracy of the integrative polygenic analysis; and these contributions are of considerable importance in the pathogenesis of BOTs (Figure 9). Conclusively, these findings could provide a clearer direction for understanding the pathogenic mechanisms of BOTs and contribute more potential targets for treatment, monitoring, and prevention of recurrence combined with precision medicine in the future. 


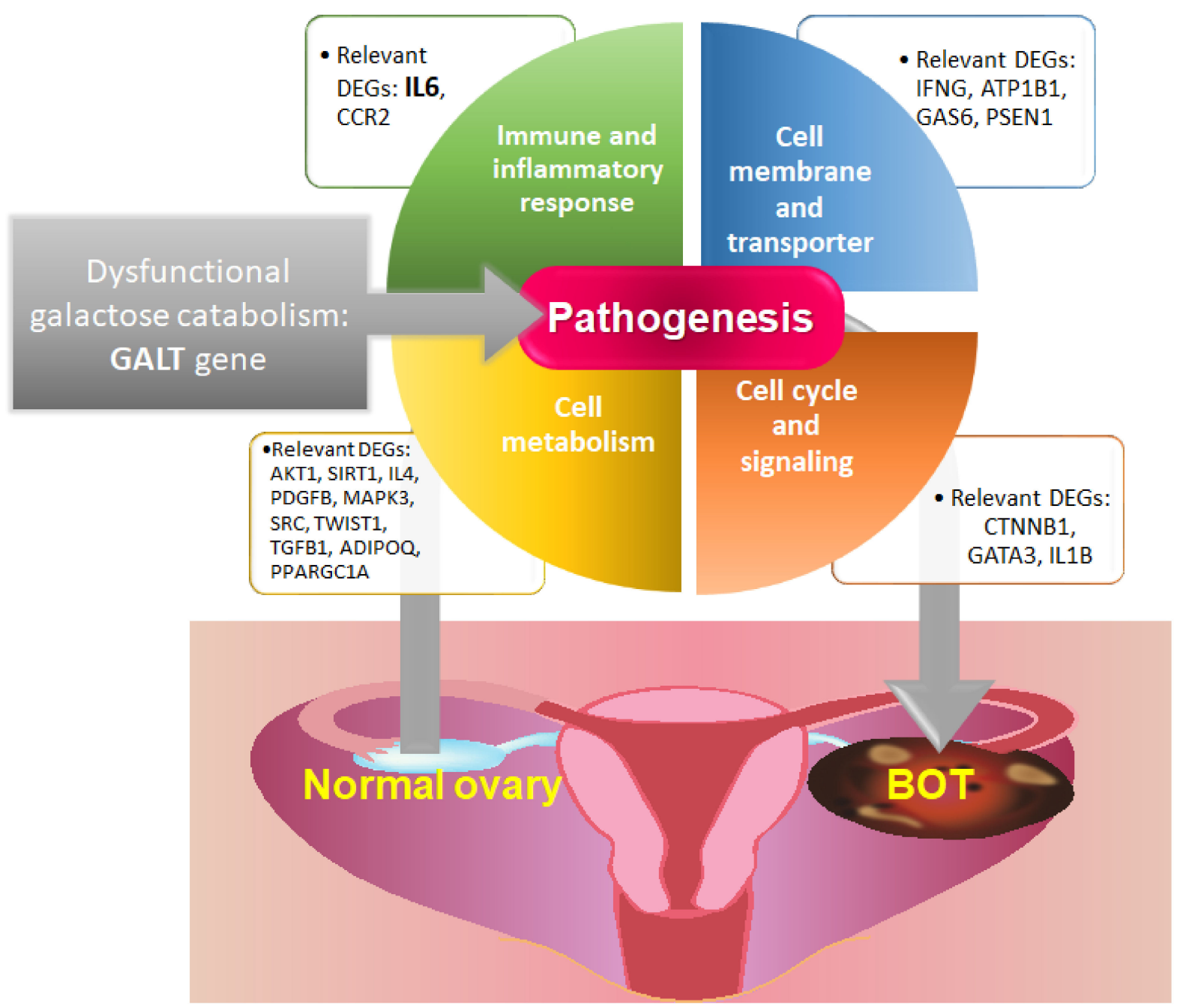

Figure 9. The proposed pathogenetic mechanisms involved in the pathogenesis of BOTs.

Supplementary Materials: The following are available online at https:/ /www.mdpi.com/article/10 $.3390 /$ ijms22084105/s1, Table S1 Detailed information of all collected samples. Table S2 The whole deregulated GO terms of All BOTs, SBOTs and MBOTs. Table S3 All scores of GALT and IL of clinical samples.

Author Contributions: Conceptualization, C.-M.C. and K.-M.S.; methodology, C.-M.C. and K.-M.S.; software, C.-M.C. and Y.-F.L.; validation, K.-H.L., T.-W.L. and K.-M.S.; formal analysis, T.-W.L. and L.-C.L.; investigation, H.-C.L. and L.-C.L.; resources, Y.-F.L. and C.-C.C.; data curation, Y.-F.L., H.-C.L. and K.-H.L.; writing - original draft preparation, C.-M.C. and K.-M.S.; writing-review and editing, K.-M.S. and C.-C.C.; visualization, K.-M.S. and Y.-F.L.; supervision, C.-M.C. and C.-C.C.; funding acquisition, C.-M.C., K.-M.S. and C.-C.C. All authors have read and agreed to the published version of the manuscript.

Funding: This research was supported individually and funded in part by the following grants from the Ministry of Science and Technology (MOST 107-2314-B-016-036), the Tri-Service General Hospital (TSGH-C108-115, TSGH-D-109106, TSGH-D-109189 and TSGH-D-110172), the Teh-Tzer Study Group for Human Medical Research Foundation, the Cheng-Hsin General Hospital, the Taipei Veterans General Hospital (V109E-005-5(110)) and Taipei Veterans General Hospital, Tri-Service General Hospital, Academia Sinica Joint Research Programs (VTA110-T-4-1 and VTA110-V5-1-2).

Institutional Review Board Statement: The study was conducted according to the guidelines of the Declaration of Helsinki and approved by the Institutional Review Board of the Tri-Service General Hospital, National Defense Medical Center approved the study (2-107-05-043, approved on 26 October 2018; 2-108-05-091, approved on 20 May 2019). 
Informed Consent Statement: Informed consent was obtained from all subjects involved in the study.

Data Availability Statement: The datasesets of microarrays expression profiles are publically available in the National Center for Biotechnology Information (NCBI) Gene Expression Omnibus (GEO) repository (https://www.ncbi.nlm.nih.gov/geo/, accessed on 15 April 2021).

Acknowledgments: We would like to thank Hui-Yin Su and Kuo-Chih Su for figure editing.

Conflicts of Interest: The authors declare no conflict of interest.

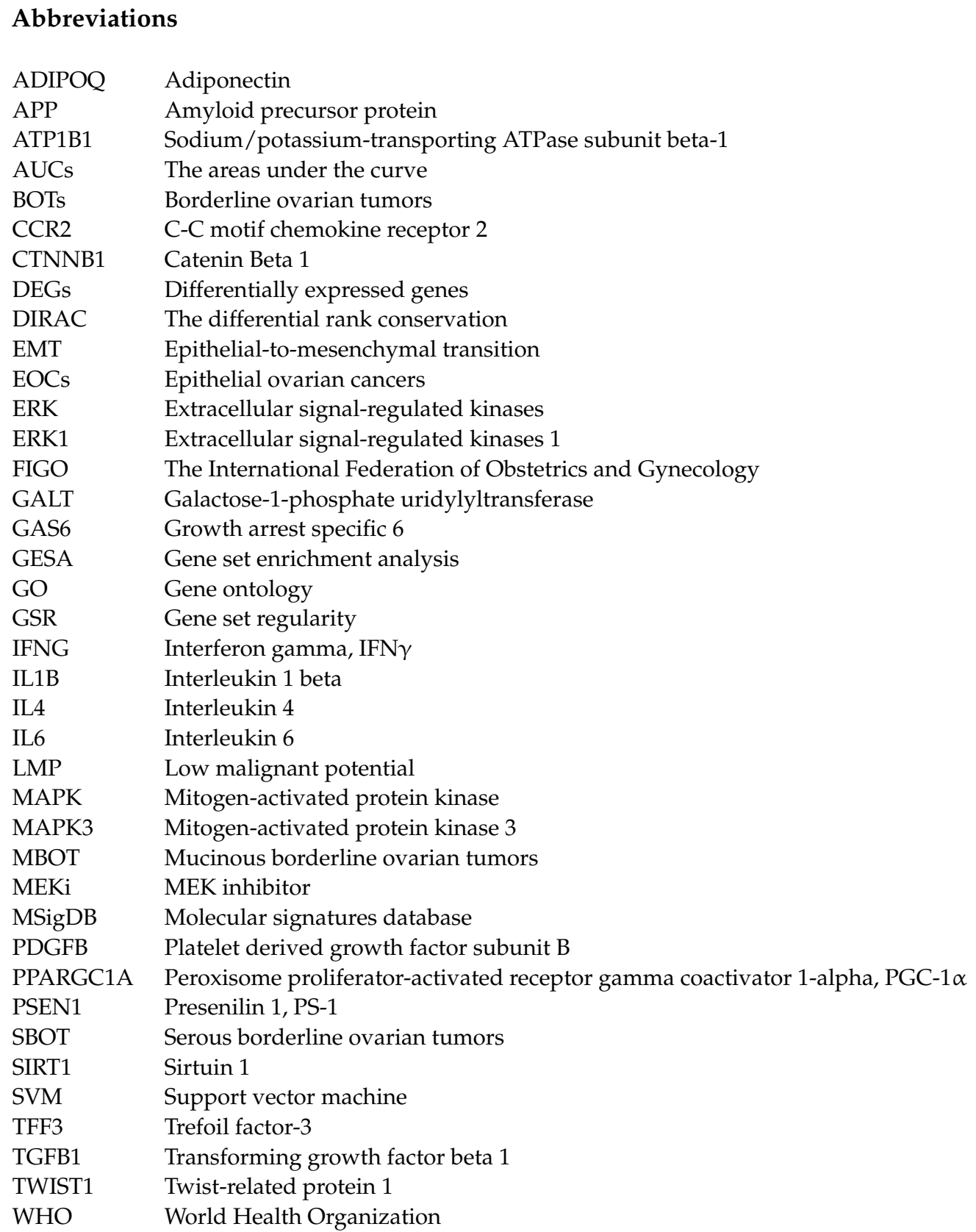

\section{References}

1. Harter, P.; Gershenson, D.; Lhomme, C.; Lecuru, F.; Ledermann, J.; Provencher, D.M.; Mezzanzanica, D.; Quinn, M.; Maenpaa, J.; Kim, J.-W. Gynecologic Cancer InterGroup (GCIG) consensus review for ovarian tumors of low malignant potential (borderline ovarian tumors). Int. J. Gynecol. Cancer 2014, 24 (Suppl. 3). [CrossRef] [PubMed]

2. Taylor, H.C. Malignant and semimalignant tumors of the ovary. Surg. Gynecol. Obs. 1929, 48, 204-230. 
3. Carcangiu, M.; Kurman, R.J.; Carcangiu, M.L.; Herrington, C.S. WHO Classification of Tumours of Female Reproductive Organs; International Agency for Research on Cancer: Lyon, France, 2014.

4. Hauptmann, S.; Friedrich, K.; Redline, R.; Avril, S. Ovarian borderline tumors in the 2014 WHO classification: Evolving concepts and diagnostic criteria. Virchows Arch. 2017, 470, 125-142. [CrossRef]

5. $\quad$ Silverberg, S.G.; Bell, D.A.; Kurman, R.J.; Seidman, J.D.; Prat, J.; Ronnett, B.M.; Copeland, L.; Silva, E.; Gorstein, F.; Young, R.H. Borderline ovarian tumors: Key points and workshop summary. Hum. Pathol. 2004, 35, 910-917. [CrossRef] [PubMed]

6. Du Bois, A.; Trillsch, F.; Mahner, S.; Heitz, F.; Harter, P. Management of borderline ovarian tumors. Ann. Oncol. 2016, 27 , i20-i22. [CrossRef] [PubMed]

7. Lalwani, N.; Shanbhogue, A.K.; Vikram, R.; Nagar, A.; Jagirdar, J.; Prasad, S.R. Current update on borderline ovarian neoplasms. Am. J. Roentgenol. 2010, 194, 330-336. [CrossRef] [PubMed]

8. Trillsch, F.; Mahner, S.; Ruetzel, J.; Harter, P.; Ewald-Riegler, N.; Jaenicke, F.; Du Bois, A. Clinical management of borderline ovarian tumors. Expert Rev. Anticancer Ther. 2010, 10, 1115-1124. [CrossRef] [PubMed]

9. Song, T.; Lee, Y.-Y.; Choi, C.H.; Kim, T.-J.; Lee, J.-W.; Bae, D.-S.; Kim, B.-G. Histologic distribution of borderline ovarian tumors worldwide: A systematic review. J. Gynecol. Oncol. 2013, 24, 44-51. [CrossRef]

10. Loizzi, V.; Selvaggi, L.; Leone, L.; Latorre, D.; Scardigno, D.; Magazzino, F.; Cormio, G. Borderline epithelial tumors of the ovary: Experience of 55 patients. Oncol. Lett. 2015, 9, 912-914. [CrossRef]

11. Yasmeen, S.; Hannan, A.; Sheikh, F.; Syed, A.A.; Siddiqui, N. Borderline tumors of the ovary: A clinicopathological study. Pak. J. Med. Sci. 2017, 33, 369. [CrossRef]

12. Jones, M.B. Borderline ovarian tumors: Current concepts for prognostic factors and clinical management. Clin. Obstet. Gynecol. 2006, 49, 517-525. [CrossRef]

13. Nayyar, N.; Lakhwani, P.; Goel, A.; Pande, P.K.; Kumar, K. Management of Borderline Ovarian Tumors-Still a Gray Zone. Indian J. Surg. Oncol. 2017, 8, 607-614. [CrossRef]

14. Trimble, C.; Kosary, C.; Trimble, E. Long-term survival and patterns of care in women with ovarian carcinoma: A population-based analysis. Gynecol. Oncol. 2002, 86, 34-37. [CrossRef]

15. Sobiczewski, P.; Kupryjanczyk, J.; Michalski, W.; Śpiewankiewicz, B. The evaluation of risk factors associated with relapse and recurrence of borderline ovarian tumors with long-term follow-up. Int. J. Gynecol. Cancer 2016, 26, 1053-1061. [CrossRef]

16. Berek, J.S.; Kehoe, S.T.; Kumar, L.; Friedlander, M. Cancer of the ovary, fallopian tube, and peritoneum. Int. J. Gynecol. Obstet. 2018, 143, 59-78. [CrossRef]

17. Sun, Y.; Xu, J.; Jia, X. The Diagnosis, Treatment, Prognosis and Molecular Pathology of Borderline Ovarian Tumors: Current Status and Perspectives. Cancer Manag. Res. 2020, 12, 3651-3659. [CrossRef]

18. Winter, W.E., III; Kucera, P.R.; Rodgers, W.; McBroom, J.W.; Olsen, C.; Maxwell, G.L. Surgical staging in patients with ovarian tumors of low malignant potential. Obstet. Gynecol. 2002, 100, 671-676.

19. Vasconcelos, I.; de Sousa Mendes, M. Conservative surgery in ovarian borderline tumours: A meta-analysis with emphasis on recurrence risk. Eur. J. Cancer 2015, 51, 620-631. [CrossRef]

20. Trillsch, F.; Mahner, S.; Woelber, L.; Vettorazzi, E.; Reuss, A.; Ewald-Riegler, N.; de Gregorio, N.; Fotopoulou, C.; Schmalfeldt, B.; Burges, A. Age-dependent differences in borderline ovarian tumours (BOT) regarding clinical characteristics and outcome: Results from a sub-analysis of the Arbeitsgemeinschaft Gynaekologische Onkologie (AGO) ROBOT study. Ann. Oncol. 2014, 25, 1320-1327. [CrossRef]

21. Zanetta, G.; Rota, S.; Chiari, S.; Bonazzi, C.; Bratina, G.; Mangioni, C. Behavior of borderline tumors with particular interest to persistence, recurrence, and progression to invasive carcinoma: A prospective study. J. Clin. Oncol. 2001, 19, 2658-2664. [CrossRef]

22. Romeo, M.; Pons, F.; Barretina, P.; Radua, J. Incomplete staging surgery as a major predictor of relapse of borderline ovarian tumor. World J. Surg. Oncol. 2013, 11, 1-7. [CrossRef] [PubMed]

23. Barnhill, D.R.; Kurman, R.J.; Brady, M.F.; Omura, G.A.; Yordan, E.; Given, F.T.; Kucera, P.R.; Roman, L.D. Preliminary analysis of the behavior of stage I ovarian serous tumors of low malignant potential: A Gynecologic Oncology Group study. J. Clin. Oncol. 1995, 13, 2752-2756. [CrossRef] [PubMed]

24. Sutton, G.P.; Bundy, B.N.; Omura, G.A.; Yordan, E.L.; Beecham, J.B.; Bonfiglio, T. Stage III ovarian tumors of low malignant potential treated with cisplatin combination therapy (a Gynecologic Oncology Group study). Gynecol. Oncol. 1991, 41, 230-233. [CrossRef]

25. Barakat, R.R.; Benjamin, I.; Lewis, J.L., Jr.; Saigo, P.E.; Curtin, J.P.; Hoskins, W.J. Platinum-based chemotherapy for advanced-stage serous ovarian carcinoma of low malignant potential. Gynecol. Oncol. 1995, 59, 390-393. [CrossRef] [PubMed]

26. Ronnett, B.M.; Kurman, R.J.; Zahn, C.M.; Shmookler, B.M.; Jablonski, K.A.; Kass, M.E.; Sugarbaker, P.H. Pseudomyxoma peritonei in women: A clinicopathologic analysis of 30 cases with emphasis on site of origin, prognosis, and relationship to ovarian mucinous tumors of low malignant potential. Hum. Pathol. 1995, 26, 509-524. [CrossRef]

27. Trope, C.; Kaern, J.; Vergote, I.; Kristensen, G.; Abeler, V. Are borderline tumors of the ovary overtreated both surgically and systemically? A review of four prospective randomized trials including 253 patients with borderline tumors. Gynecol. Oncol. 1993, 51, 236-243. [CrossRef]

28. Fathalla, M. Incessant ovulation-a factor in ovarian neoplasia. Lancet 1971, 2, 163. [CrossRef] 
29. Van Leeuwen, F.; Klip, H.; Mooij, T.M.; Van De Swaluw, A.; Lambalk, C.B.; Kortman, M.; Laven, J.; Jansen, C.; Helmerhorst, F.; Cohlen, B. Risk of borderline and invasive ovarian tumours after ovarian stimulation for in vitro fertilization in a large Dutch cohort. Hum. Reprod. 2011, 26, 3456-3465. [CrossRef]

30. Riman, T.; Dickman, P.W.; Nilsson, S.; Correia, N.; Nordlinder, H.; Magnusson, C.M.; Persson, I.R. Risk factors for epithelial borderline ovarian tumors: Results of a Swedish case-control study. Gynecol. Oncol. 2001, 83, 575-585. [CrossRef]

31. Kurman, R.J. Blaustein's Pathology of the Female Genital Tract; Springer Science \& Business Media: Berlin/Heidelberg, Germany, 2013; pp. 529-578.

32. Mayr, D.; Hirschmann, A.; Löhrs, U.; Diebold, J. KRAS and BRAF mutations in ovarian tumors: A comprehensive study of invasive carcinomas, borderline tumors and extraovarian implants. Gynecol. Oncol. 2006, 103, 883-887. [CrossRef]

33. Ho, C.-L.; Kurman, R.J.; Dehari, R.; Wang, T.-L.; Shih, I.-M. Mutations of BRAF and KRAS precede the development of ovarian serous borderline tumors. Cancer Res. 2004, 64, 6915-6918. [CrossRef]

34. Anglesio, M.S.; Arnold, J.M.; George, J.; Tinker, A.V.; Tothill, R.; Waddell, N.; Simms, L.; Locandro, B.; Fereday, S.; Traficante, N. Mutation of ERBB2 provides a novel alternative mechanism for the ubiquitous activation of RAS-MAPK in ovarian serous low malignant potential tumors. Mol. Cancer Res. 2008, 6, 1678-1690. [CrossRef]

35. Seong, S.J.; Kim, D.H.; Kim, M.K.; Song, T. Controversies in borderline ovarian tumors. J. Gynecol. Oncol. 2015, 26, 343-349. [CrossRef]

36. El-Balat, A.; Schmeil, I.; Gasimli, K.; Sänger, N.; Karn, T.; Ahr, A.; Becker, S.; Arsenic, R.; Holtrich, U.; Engels, K. Claudin-1 is linked to presence of implants and micropapillary pattern in serous borderline epithelial tumours of the ovary. J. Clin. Pathol. 2018, 71, 1060-1064. [CrossRef]

37. McAlpine, J.N.; Wiegand, K.C.; Vang, R.; Ronnett, B.M.; Adamiak, A.; Köbel, M.; Kalloger, S.E.; Swenerton, K.D.; Huntsman, D.G.; Gilks, C.B. HER2 overexpression and amplification is present in a subset of ovarian mucinous carcinomas and can be targeted with trastuzumab therapy. BMC Cancer 2009, 9, 1-12. [CrossRef]

38. Mackenzie, R.; Kommoss, S.; Winterhoff, B.J.; Kipp, B.R.; Garcia, J.J.; Voss, J.; Halling, K.; Karnezis, A.; Senz, J.; Yang, W. Targeted deep sequencing of mucinous ovarian tumors reveals multiple overlapping RAS-pathway activating mutations in borderline and cancerous neoplasms. BMC Cancer 2015, 15, 415. [CrossRef]

39. Malpica, A.; Wong, K.-K. The molecular pathology of ovarian serous borderline tumors. Ann. Oncol. 2016, 27 (Suppl. 1), i16-i19. [CrossRef]

40. Ozretić, P.; Trnski, D.; Musani, V.; Maurac, I.; Kalafatić, D.; Orešković, S.; Levanat, S.; Sabol, M. Non-canonical Hedgehog signaling activation in ovarian borderline tumors and ovarian carcinomas. Int. J. Oncol. 2017, 51, 1869-1877. [CrossRef]

41. Grisham, R.N.; Iyer, G.; Sala, E.; Zhou, Q.; Iasonos, A.; DeLair, D.; Hyman, D.M.; Aghajanian, C. Bevacizumab shows activity in patients with low-grade serous ovarian and primary peritoneal cancer. Int. J. Gynecol. Cancer 2014, 24, 1010-1014. [CrossRef]

42. Shih, I.-M.; Kurman, R.J. Molecular pathogenesis of ovarian borderline tumors: New insights and old challenges. Clin. Cancer Res. 2005, 11, 7273-7279. [CrossRef]

43. Gershenson, D.M. Molecular targeting of low-grade serous and mucinous carcinomas of the ovary or peritoneum. Transl. Cancer Res. 2015, 4, 29-39.

44. Hirst, J.; Crow, J.; Godwin, A. Ovarian cancer genetics: Subtypes and risk factors. Ovarian Cancer. Pathog. Treat 2018. [CrossRef]

45. Chang, C.-M.; Chuang, C.-M.; Wang, M.-L.; Yang, Y.-P.; Chuang, J.-H.; Yang, M.-J.; Yen, M.-S.; Chiou, S.-H.; Chang, C.-C. Gene set- based integrative analysis revealing two distinct functional regulation patterns in four common subtypes of epithelial ovarian cancer. Int. J. Mol. Sci. 2016, 17, 1272. [CrossRef]

46. Chang, C.-M.; Chuang, C.-M.; Wang, M.-L.; Yang, M.-J.; Chang, C.-C.; Yen, M.-S.; Chiou, S.-H. Gene set-based functionome analysis of pathogenesis in epithelial ovarian serous carcinoma and the molecular features in different FIGO stages. Int. J. Mol. Sci. 2016, 17, 886. [CrossRef]

47. Chang, C.-M.; Wang, M.-L.; Lu, K.-H.; Yang, Y.-P.; Juang, C.-M.; Wang, P.-H.; Hsu, R.-J.; Yu, M.-H.; Chang, C.-C. Integrating the dysregulated inflammasome-based molecular functionome in the malignant transformation of endometriosis-associated ovarian carcinoma. Oncotarget 2018, 9, 3704. [CrossRef]

48. Chang, C.-M.; Yang, Y.-P.; Chuang, J.-H.; Chuang, C.-M.; Lin, T.-W.; Wang, P.-H.; Yu, M.-H.; Chang, C.-C. Discovering the deregulated molecular functions involved in malignant transformation of endometriosis to endometriosis-associated ovarian carcinoma using a data-driven, function-based analysis. Int. J. Mol. Sci. 2017, 18, 2345. [CrossRef]

49. Chang, C.-C.; Su, K.-M.; Lu, K.-H.; Lin, C.-K.; Wang, P.-H.; Li, H.-Y.; Wang, M.-L.; Lin, C.-K.; Yu, M.-H.; Chang, C.-M. Key immunological functions involved in the progression of epithelial ovarian serous carcinoma discovered by the gene ontologybased immunofunctionome analysis. Int. J. Mol. Sci. 2018, 19, 3311. [CrossRef]

50. Su, K.-M.; Lin, T.-W.; Liu, L.-C.; Yang, Y.-P.; Wang, M.-L.; Tsai, P.-H.; Wang, P.-H.; Yu, M.-H.; Chang, C.-M.; Chang, C.-C. The Potential Role of Complement System in the Progression of Ovarian Clear Cell Carcinoma Inferred from the Gene Ontology-Based Immunofunctionome Analysis. Int. J. Mol. Sci. 2020, 21, 2824. [CrossRef]

51. Liberzon, A.; Birger, C.; Thorvaldsdóttir, H.; Ghandi, M.; Mesirov, J.P.; Tamayo, P. The molecular signatures database hallmark gene set collection. Cell Syst. 2015, 1, 417-425. [CrossRef]

52. Dessimoz, C.; Skunca, N. The Gene Ontology Handbook; Methods in Molecular Biology; Springer: Berlin/Heidelberg, Germany, 2017; pp. 3-37. 
53. Schröder, W.; Ruppert, C.; Bender, H. Concomitant measurements of interleukin-6 (IL-6) in serum and peritoneal fluid of patients with benign and malignant ovarian tumors. Eur. J. Obstet. Gynecol. Reprod. Biol. 1994, 56, 43-46. [CrossRef]

54. Plewka, D.; Kowalczyk, A.E.; Jakubiec-Bartnik, B.; Morek, M.; Bogunia, E.; Kmiec, A.; Wierzbicki, P.M.; Plewka, A. Immunohistochemical visualization of pro-inflammatory cytokines and enzymes in ovarian tumors. Folia Histochem. Et Cytobiol. 2014, 52, 124-137. [CrossRef] [PubMed]

55. Browning, L.; Patel, M.R.; Horvath, E.B.; Tawara, K.; Jorcyk, C.L. IL-6 and ovarian cancer: Inflammatory cytokines in promotion of metastasis. Cancer Manag. Res. 2018, 10, 6685. [CrossRef] [PubMed]

56. Baci, D.; Bosi, A.; Gallazzi, M.; Rizzi, M.; Noonan, D.M.; Poggi, A.; Bruno, A.; Mortara, L. The Ovarian Cancer Tumor Immune Microenvironment (TIME) as Target for Therapy: A Focus on Innate Immunity Cells as Therapeutic Effectors. Int. J. Mol. Sci. 2020, 21, 3125. [CrossRef] [PubMed]

57. Lee, J.M.; Dedhar, S.; Kalluri, R.; Thompson, E.W. The epithelial-mesenchymal transition: New insights in signaling, development, and disease. J. Cell Biol. 2006, 172, 973-981. [CrossRef]

58. Lili, L.N.; Matyunina, L.V.; Walker, L.D.; Wells, S.L.; Benigno, B.B.; McDonald, J.F. Molecular profiling supports the role of epithelial-to-mesenchymal transition (EMT) in ovarian cancer metastasis. J. Ovarian Res. 2013, 6, 1-7. [CrossRef]

59. Yi, B.-R.; Kim, T.-H.; Kim, Y.-S.; Choi, K.-C. Alteration of epithelial-mesenchymal transition markers in human normal ovaries and neoplastic ovarian cancers. Int. J. Oncol. 2015, 46, 272-280. [CrossRef]

60. Loret, N.; Denys, H.; Tummers, P.; Berx, G. The role of epithelial-to-mesenchymal plasticity in ovarian cancer progression and therapy resistance. Cancers 2019, 11, 838. [CrossRef]

61. Bhuyan, G.; Arora, R.; Ahluwalia, C.; Sharma, P. Epithelial-mesenchymal transition in serous and mucinous epithelial tumors of the ovary. J. Cancer Res. Ther. 2019, 15, 1309.

62. Ashrafizadeh, M.; Zarrabi, A.; Hushmandi, K.; Kalantari, M.; Mohammadinejad, R.; Javaheri, T.; Sethi, G. Association of the epithelial-mesenchymal transition (EMT) with cisplatin resistance. Int. J. Mol. Sci. 2020, 21, 4002. [CrossRef]

63. Pavlova, N.N.; Thompson, C.B. The emerging hallmarks of cancer metabolism. Cell Metab. 2016, 23, 27-47. [CrossRef]

64. Berek, J.; Martinez-Maza, O.; Hamilton, T.; Trope, C.; Kaern, J.; Baak, J.; Rustin, G. Molecular and biological factors in the pathogenesis of ovarian cancer. Ann. Oncol. 1993, 4, S3-S16. [CrossRef]

65. Pinciroli, P.; Alberti, C.; Sensi, M.; Canevari, S.; Tomassetti, A. An IL6-correlated signature in serous epithelial ovarian cancer associates with growth factor response. BMC Genom. 2013, 14, 508. [CrossRef]

66. Cai, D.L.; Jin, L.-P. Immune cell population in ovarian tumor microenvironment. J. Cancer 2017, 8, 2915. [CrossRef]

67. Tan, J.H.; Ludeman, J.P.; Wedderburn, J.; Canals, M.; Hall, P.; Butler, S.J.; Taleski, D.; Christopoulos, A.; Hickey, M.J.; Payne, R.J. Tyrosine sulfation of chemokine receptor CCR2 enhances interactions with both monomeric and dimeric forms of the chemokine monocyte chemoattractant protein-1 (MCP-1). J. Biol. Chem. 2013, 288, 10024-10034. [CrossRef]

68. Hao, Q.; Vadgama, J.V.; Wang, P. CCL2/CCR2 signaling in cancer pathogenesis. Cell Commun. Signal. 2020, 18, 1-13. [CrossRef]

69. Binder, P.S.; Cullinan, D.; Nywening, T.; Wilkinson-Ryan, I.; Belt, B.; Goedegebuure, P.; Powell, M.A.; Mutch, D.G.; Hawkins, W. CCR2 blockade alters the tumor microenvironment immune infiltrate and enhances anti-tumor activity in ovarian cancer. Gynecol. Oncol. 2017, 145, 36. [CrossRef]

70. Windbichler, G.; Hausmaninger, H.; Stummvoll, W.; Graf, A.; Kainz, C.; Lahodny, J.; Denison, U.; Müller-Holzner, E.; Marth, C. Interferon-gamma in the first-line therapy of ovarian cancer: A randomized phase III trial. Br. J. Cancer 2000, 82, 1138-1144. [CrossRef]

71. Hao, D.; Liu, J.; Chen, M.; Li, J.; Wang, L.; Li, X.; Zhao, Q.; Di, L.-J. Immunogenomic analyses of advanced serous ovarian cancer reveal immune score is a strong prognostic factor and an indicator of chemosensitivity. Clin. Cancer Res. 2018, $24,3560-3571$. [CrossRef]

72. Tummala, R.; Wolle, D.; Barwe, S.P.; Sampson, V.B.; Rajasekaran, A.K.; Pendyala, L. Expression of Na, K-ATPase- $\beta 1$ subunit increases uptake and sensitizes carcinoma cells to oxaliplatin. Cancer Chemother. Pharmacol. 2009, 64, 1187-1194. [CrossRef]

73. Rajasekaran, S.; Palmer, L.; Quan, K.; Harper, J.F.; Ball, W.J., Jr.; Bander, N.H.; Peralta, S.A.; Rajasekaran, A.K. Na+, K+ ATPase betasubunit is required for epithelial polarization, suppression of invasion, and cell motility. Mol. Biol. Cell 2001, 12, $279-295$. [CrossRef]

74. Buehler, M.; Tse, B.; Leboucq, A.; Jacob, F.; Caduff, R.; Fink, D.; Goldstein, D.R.; Heinzelmann-Schwarz, V. Meta-analysis of microarray data identifies GAS6 expression as an independent predictor of poor survival in ovarian cancer. BioMed Res. Int. 2013. [CrossRef] [PubMed]

75. Antony, J.; Tan, T.Z.; Kelly, Z.; Low, J.; Choolani, M.; Recchi, C.; Gabra, H.; Thiery, J.P.; Huang, R.Y.-J. The GAS6-AXL signaling network is a mesenchymal (Mes) molecular subtype-specific therapeutic target for ovarian cancer. Sci. Signal. 2016, 9, ra97. [CrossRef] [PubMed]

76. Xu, Y.; Cheng, L.; Dai, H.; Zhang, R.; Wang, M.; Shi, T.; Sun, M.; Cheng, X.; Wei, Q. Variants in Notch signalling pathway genes, PSEN 1 and MAML 2, predict overall survival in Chinese patients with epithelial ovarian cancer. J. Cell. Mol. Med. 2018, 22, 4975-4984. [CrossRef] [PubMed]

77. Zhang, H.; Jiang, R.; Zhou, J.; Wang, J.; Xu, Y.; Zhang, H.; Gu, Y.; Fu, F.; Shen, Y.; Zhang, G. CTL Attenuation Regulated by PS1 in Cancer-Associated Fibroblast. Front. Immunol. 2020, 11, 999. [CrossRef]

78. Kurman, R.J.; Shih, I.-M. Molecular pathogenesis and extraovarian origin of epithelial ovarian cancer-shifting the paradigm. Hum. Pathol. 2011, 42, 918-931. [CrossRef] 
79. Prat, J. New insights into ovarian cancer pathology. Ann. Oncol. 2012, 23 (Suppl. 10), x111-x117. [CrossRef]

80. Koshiyama, M.; Matsumura, N.; Konishi, I. Recent concepts of ovarian carcinogenesis: Type I and type II. Biomed Res. Int. 2014. [CrossRef]

81. Stemke-Hale, K.; Shipman, K.; Kitsou-Mylona, I.; De Castro, D.G.; Hird, V.; Brown, R.; Flanagan, J.; Gabra, H.; Mills, G.B.; Agarwal, R. Frequency of mutations and polymorphisms in borderline ovarian tumors of known cancer genes. Mod. Pathol. 2013, 26, 544-552. [CrossRef]

82. Ordóñez, N.G. Value of GATA3 immunostaining in tumor diagnosis: A review. Adv. Anat. Pathol. 2013, 20, 352-360. [CrossRef]

83. Chen, H.J.; Huang, R.L.; Liew, P.L.; Su, P.H.; Chen, L.Y.; Weng, Y.C.; Chang, C.C.; Wang, Y.C.; Chan, M.W.Y.; Lai, H.C. GATA3 as a master regulator and therapeutic target in ovarian high-grade serous carcinoma stem cells. Int. J. Cancer 2018, 143, 3106-3119. [CrossRef]

84. Schauer, I.G.; Zhang, J.; Xing, Z.; Guo, X.; Mercado-Uribe, I.; Sood, A.K.; Huang, P.; Liu, J. Interleukin-1 $\beta$ promotes ovarian tumorigenesis through a p53/NF-kB-mediated inflammatory response in stromal fibroblasts. Neoplasia 2013, 15, 409-IN18. [CrossRef]

85. Wang, Y.-Z.; Qiu, S.-C. Prediction of key genes in ovarian cancer treated with decitabine based on network strategy. Oncol. Rep. 2016, 35, 3548-3558. [CrossRef]

86. Litmanovich, A.; Khazim, K.; Cohen, I. The role of interleukin-1 in the pathogenesis of cancer and its potential as a therapeutic target in clinical practice. Oncol. Ther. 2018, 6, 109-127. [CrossRef]

87. Cheng, J.; Auersperg, N.; Leung, P. Inhibition of p53 induces invasion of serous borderline ovarian tumor cells by accentuating PI3K/Akt-mediated suppression of E-cadherin. Oncogene 2011, 30, 1020-1031. [CrossRef]

88. Jang, K.Y.; Kim, K.S.; Hwang, S.H.; Kwon, K.S.; Kim, K.R.; Park, H.S.; Park, B.-H.; Chung, M.J.; Kang, M.J.; Lee, D.G. Expression and prognostic significance of SIRT1 in ovarian epithelial tumours. Pathology 2009, 41, 366-371. [CrossRef]

89. Bai, H.; Cao, D.; Yang, J.; Li, M.; Zhang, Z.; Shen, K. Genetic and epigenetic heterogeneity of epithelial ovarian cancer and the clinical implications for molecular targeted therapy. J. Cell. Mol. Med. 2016, 20, 581-593. [CrossRef]

90. Yang, Q.; Yang, Y.; Zhou, N.; Tang, K.; Lau, W.B.; Lau, B.; Wang, W.; Xu, L.; Yang, Z.; Huang, S. Epigenetics in ovarian cancer: Premise, properties, and perspectives. Mol. Cancer 2018, 17, 109. [CrossRef]

91. Li, Z.; Jiang, J.; Wang, Z.; Zhang, J.; Xiao, M.; Wang, C.; Lu, Y.; Qin, Z. Endogenous interleukin-4 promotes tumor development by increasing tumor cell resistance to apoptosis. Cancer Res. 2008, 68, 8687-8694. [CrossRef]

92. Versnel, M.A.; Haarbrink, M.; Langerak, A.W.; de Laat, P.A.; Hagemeijer, A.; van der Kwast, T.H.; van den Berg-Bakker, L.A.; Schrier, P.I. Human ovarian tumors of epithelial origin express PDGF in vitro and in vivo. Cancer Genet. Cytogenet. 1994, 73, 60-64. [CrossRef]

93. Link, C.J., Jr.; Kohn, E.; Reed, E. The relationship between borderline ovarian tumors and epithelial ovarian carcinoma: Epidemiologic, pathologic, and molecular aspects. Gynecol. Oncol. 1996, 60, 347-354. [CrossRef]

94. Madsen, C.V.; Steffensen, K.D.; Olsen, D.A.; Waldstrøm, M.; Søgaard, C.H.; Brandslund, I.; Jakobsen, A. Serum platelet-derived growth factor and fibroblast growth factor in patients with benign and malignant ovarian tumors. Anticancer Res. 2012, 32, 3817-3825.

95. Czekierdowska, S.; Stachowicz, N.; Chróściel, M.; Czekierdowski, A. Proliferation and maturation of intratumoral blood vessels in women with malignant ovarian tumors assessed with cancer stem cells marker nestin and platelet derived growth factor PDGF-B. Ginekol. Pol. 2017, 88, 120-128. [CrossRef]

96. Sieben, N.L.; Oosting, J.; Flanagan, A.M.; Prat, J.; Roemen, G.M.; Kolkman-Uljee, S.M.; van Eijk, R.; Cornelisse, C.J.; Fleuren, G.J.; van Engeland, M. Differential gene expression in ovarian tumors reveals Dusp 4 and Serpina 5 as key regulators for benign behavior of serous borderline tumors. J. Clin. Oncol. 2005, 23, 7257-7264. [CrossRef]

97. Ohnishi, K.; Nakayama, K.; Ishikawa, M.; Ishibashi, T.; Yamashita, H.; Nakamura, K.; Minamoto, T.; Iida, K.; Razia, S.; Ishikawa, N. Mucinous borderline ovarian tumors with BRAF V600E mutation may have low risk for progression to invasive carcinomas. Arch. Gynecol. Obstet. 2020, 302, 487-495. [CrossRef]

98. Manek, R.; Pakzamir, E.; Mhawech-Fauceglia, P.; Pejovic, T.; Sowter, H.; Gayther, S.A.; Lawrenson, K. Targeting Src in endometriosis-associated ovarian cancer. Oncogenesis 2016, 5, e251. [CrossRef]

99. Irby, R.B.; Yeatman, T.J. Role of Src expression and activation in human cancer. Oncogene 2000, 19, 5636-5642. [CrossRef]

100. Hosono, S.; Kajiyama, H.; Terauchi, M.; Shibata, K.; Ino, K.; Nawa, A.; Kikkawa, F. Expression of Twist increases the risk for recurrence and for poor survival in epithelial ovarian carcinoma patients. Br. J. Cancer 2007, 96, 314-320. [CrossRef] [PubMed]

101. Yoshida, J.; Horiuchi, A.; Kikuchi, N.; Hayashi, A.; Osada, R.; Ohira, S.; Shiozawa, T.; Konishi, I. Changes in the expression of E-cadherin repressors, Snail, Slug, SIP1, and Twist, in the development and progression of ovarian carcinoma: The important role of Snail in ovarian tumorigenesis and progression. Med. Mol. Morphol. 2009, 42, 82-91. [CrossRef] [PubMed]

102. Sadlecki, P.; Jóźwicki, J.; Antosik, P.; Grabiec, M. Expression of selected epithelial-mesenchymal transition transcription factors in serous borderline ovarian tumors and type I ovarian cancers. Tumor Biol. 2018, 40, 1010428318784807. [CrossRef] [PubMed]

103. El-Etreby, N.M.; Ghazy, A.A.; Rashad, R. Prohibitin: Targeting peptide coupled to ovarian cancer, luteinization and TGF- $\beta$ pathways. J. Ovarian Res. 2017, 10,1-7. [CrossRef]

104. Cheng, J.-C.; Auersperg, N.; Leung, P.C. TGF-beta induces serous borderline ovarian tumor cell invasion by activating EMT but triggers apoptosis in low-grade serous ovarian carcinoma cells. PLoS ONE 2012, 7, e42436. [CrossRef] 
105. Ray, A.; Fornsaglio, J.; Dogan, S.; Hedau, S.; Naik, S.D.; De, A. Gynaecological cancers and leptin: A focus on the endometrium and ovary. Factsviews Vis. Obgyn 2018, 10, 5.

106. Jin, J.H.; Kim, H.-J.; Kim, C.Y.; Kim, Y.H.; Ju, W.; Kim, S.C. Association of plasma adiponectin and leptin levels with the development and progression of ovarian cancer. Obstet. Gynecol. Sci. 2016, 59, 279-285. [CrossRef]

107. Tumminia, A.; Vinciguerra, F.; Parisi, M.; Graziano, M.; Sciacca, L.; Baratta, R.; Frittitta, L. Adipose tissue, obesity and adiponectin: Role in endocrine cancer risk. Int. J. Mol. Sci. 2019, 20, 2863. [CrossRef]

108. Tiwari, A.; Ocon-Grove, O.M.; Hadley, J.A.; Giles, J.R.; Johnson, P.A.; Ramachandran, R. Expression of adiponectin and its receptors is altered in epithelial ovarian tumors and ascites-derived ovarian cancer cell lines. Int. J. Gynecol. Cancer 2015, 25, 399-406. [CrossRef]

109. Zhang, Y.; Ba, Y.; Liu, C.; Sun, G.; Ding, L.; Gao, S.; Hao, J.; Yu, Z.; Zhang, J.; Zen, K. PGC-1 $\alpha$ induces apoptosis in human epithelial ovarian cancer cells through a PPAR $\gamma$-dependent pathway. Cell Res. 2007, 17, 363-373. [CrossRef]

110. Gabrielson, M.; Björklund, M.; Carlson, J.; Shoshan, M. Expression of mitochondrial regulators PGC1 $\alpha$ and TFAM as putative markers of subtype and chemoresistance in epithelial ovarian carcinoma. PLoS ONE 2014, 9, e107109.

111. Mastropasqua, F.; Girolimetti, G.; Shoshan, M. PGC1 $\alpha$ : Friend or foe in cancer? Genes 2018, 9, 48. [CrossRef]

112. Huang, X.; Ruan, G.; Liu, G.; Gao, Y.; Sun, P. Immunohistochemical Analysis of PGC- $1 \alpha$ and ERR $\alpha$ Expression Reveals Their Clinical Significance in Human Ovarian Cancer. Oncotargets Ther. 2020, 13, 13055. [CrossRef]

113. Elsas, L.J.; Lai, K. The molecular biology of galactosemia. Genet. Med. 1998, 1, 40-48. [CrossRef]

114. Forges, T.; Monnier-Barbarino, P.; Leheup, B.; Jouvet, P. Pathophysiology of impaired ovarian function in galactosaemia. Hum. Reprod. Update 2006, 12, 573-584. [CrossRef]

115. Cramer, D.; Willett, W.; Bell, D.; Ng, W.; Harlow, B.; Welch, W.; Scully, R.; Knapp, R. Galactose consumption and metabolism in relation to the risk of ovarian cancer. Lancet 1989, 334, 66-71. [CrossRef]

116. Cramer, D.W.; Muto, M.G.; Reichardt, J.K.; Xu, H.; Welch, W.R.; Valles, B.; Ng, W.G. Characteristics of women with a family history of ovarian cancer. I. Galactose consumption and metabolism. Cancer 1994, 74, 1309-1317. [CrossRef]

117. Cozen, W.; Peters, R.; Reichardt, J.K.; Ng, W.; Felix, J.C.; Wan, P.; Pike, M.C. Galactose-1-phosphate uridyl transferase (GALT) genotype and phenotype, galactose consumption, and the risk of borderline and invasive ovarian cancer (United States). Cancer Causes Control 2002, 13, 113-120. [CrossRef]

118. Cramer, D.W.; Greenberg, E.R.; Titus-Ernstoff, L.; Liberman, R.F.; Welch, W.R.; Li, E.; Ng, W.G. A case-control study of galactose consumption and metabolism in relation to ovarian cancer. Cancer Epidemiol. Prev. Biomark. 2000, 9, 95-101.

119. Qin, L.; Xu, J.; Wang, P.; Hashi, A.; Hoshi, K.; Sato, A. Milk/dairy products consumption, galactose metabolism and ovarian cancer: Meta-analysis of epidemiological studies. Eur. J. Cancer Prev. 2005, 14, 13-19. [CrossRef]

120. Eddy, J.A.; Hood, L.; Price, N.D.; Geman, D. Identifying tightly regulated and variably expressed networks by Differential Rank Conservation (DIRAC). PLoS Comput. Biol. 2010, 6, e1000792. [CrossRef]

121. Robin, X.; Turck, N.; Hainard, A.; Tiberti, N.; Lisacek, F.; Sanchez, J.-C.; Müller, M. pROC: An open-source package for R and S+ to analyze and compare ROC curves. BMC Bioinform. 2011, 12, 1-8. [CrossRef]

122. Van Diest, P.J.; van Dam, P.; Henzen-Logmans, S.C.; Berns, E.; Van der Burg, M.; Green, J.; Vergote, I. A scoring system for immunohistochemical staining: Consensus report of the task force for basic research of the EORTC-GCCG. European Organization for Research and Treatment of Cancer-Gynaecological Cancer Cooperative Group. J. Clin. Pathol. 1997, 50, 801. [CrossRef]

123. Charafe-Jauffret, E.; Tarpin, C.; Bardou, V.J.; Bertucci, F.; Ginestier, C.; Braud, A.C.; Puig, B.; Geneix, J.; Hassoun, J.; Birnbaum, D. Immunophenotypic analysis of inflammatory breast cancers: Identification of an 'inflammatory signature'. J. Pathol. 2004, 202, 265-273. [CrossRef] 